\title{
Coordinated polar spacecraft, geosynchronous spacecraft, and ground-based observations of magnetopause processes and their coupling to the ionosphere
}

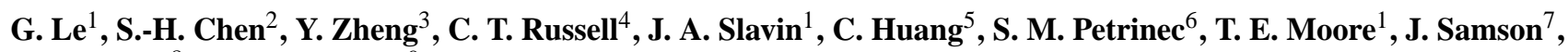 \\ H. J. Singer ${ }^{8}$, and K. Yumoto 9 \\ ${ }^{1}$ Laboratory for Extraterrestrial Physics, NASA Goddard Space Flight Center, Greenbelt, MD 20771, USA \\ ${ }^{2}$ Universities Space Research Association, NASA Goddard Space Flight Center, Greenbelt, MD 20771, USA \\ ${ }^{3}$ NRC, NASA Goddard Space Flight Center, Greenbelt, MD 20771, USA \\ ${ }^{4}$ Institute of Geophysics and Planetary Physics, University of California, Los Angeles, CA 90095-1567, USA \\ ${ }^{5}$ MIT Haystack Observatory, Westford, MA 01886, USA \\ ${ }^{6}$ Space Physics Laboratory, Lockheed Martin Advanced Technology Center, Palo Alto, CA 94304-1187, USA \\ ${ }^{7}$ Department of Physics, University of Alberta, Edmonton, Alberta, T6G 2E1, Canada \\ ${ }^{8}$ NOAA Space Environment Center, Boulder, CO 80305, USA \\ ${ }^{9}$ Space Environment Research Center, Kyushu University, 6-10-1, Hakozaki, Higashi-ku, Fukuoka 812-8581, Japan
}

Received: 27 April 2004 - Revised: 28 September 2004 - Accepted: 6 October 2004 - Published: 22 December 2004

\begin{abstract}
In this paper, we present in-situ observations of processes occurring at the magnetopause and vicinity, including surface waves, oscillatory magnetospheric field lines, and flux transfer events, and coordinated observations at geosynchronous orbit by the GOES spacecraft, and on the ground by CANOPUS and $210^{\circ}$ Magnetic Meridian (210 MM) magnetometer arrays. On 7 February 2002, during a high-speed solar wind stream, the Polar spacecraft was skimming the magnetopause in a post-noon meridian plane for $\sim 3 \mathrm{~h}$. During this interval, it made two short excursions and a few partial crossings into the magnetosheath and observed quasi-periodic cold ion bursts in the region adjacent to the magnetopause current layer. The multiple magnetopause crossings, as well as the velocity of the cold ion bursts, indicate that the magnetopause was oscillating with an $\sim 6$-min period. Simultaneous observations of Pc5 waves at geosynchronous orbit by the GOES spacecraft and on the ground by the CANOPUS magnetometer array reveal that these magnetospheric pulsations were forced oscillations of magnetic field lines directly driven by the magnetopause oscillations. The magnetospheric pulsations occurred only in a limited longitudinal region in the post-noon dayside sector, and were not a global phenomenon, as one would expect for global field line resonance. Thus, the magnetopause oscillations at the source were also limited to a localized region spanning $\sim 4 \mathrm{~h}$ in local time. These observations suggest that it is unlikely that the Kelvin-Helmholz instability and/or fluctuations in the solar wind dynamic pressure were the direct driving mechanisms for the observed boundary oscillations.
\end{abstract}

Correspondence to: G. Le

(guan.le@nasa.gov)
Instead, the likely mechanism for the localized boundary oscillations was pulsed reconnection at the magnetopause occurring along the $X$-line extending over the same 4-h region. The Pc5 band pressure fluctuations commonly seen in high-speed solar wind streams may modulate the reconnection rate as an indirect cause of the observed Pc5 pulsations. During the same interval, two flux transfer events were also observed in the magnetosphere near the oscillating magnetopause. Their ground signatures were identified in the CANOPUS data. The time delays of the FTE signatures from the Polar spacecraft to the ground stations enable us to estimate that the longitudinal extent of the reconnection $X$-line at the magnetopause was $\sim 43^{\circ}$ or $\sim 5.2 \mathrm{R}_{E}$. The coordinated in-situ and ground-based observations suggest that FTEs are produced by transient reconnection taking place along a single extended $X$-line at the magnetopause, as suggested in the models by Scholer (1988) and Southwood et al. (1988). The observations from this study suggest that the reconnection occurred in two different forms simultaneously in the same general region at the dayside magnetopause: 1) continuous reconnection with a pulsed reconnection rate, and 2) transient reconnection as flux transfer events.

Key words. Magnetospheric physics (Magnetopause, cusp and boundary layers; Magnetosphere-ionosphere interactions; MHD waves and instabilities)

\section{Introduction}

It has long been known that the motion of the magnetopause can excite long-period magnetospheric field line oscillations via field-line resonance (Southwood, 1974; 
Chen and Hasegawa, 1974a,b). The magnetopause oscillations typically have periods in the range of Pc5 pulsations $(\sim 1-10 \mathrm{~min})$. They are regarded as the primary energy source for some of the geomagnetic pulsations and transients in the Pc5 band in the magnetosphere. The penetration of these waves from the magnetopause deep into the magnetosphere is one of the most important mass and energy transport mechanisms in solar wind-magnetosphere-ionosphere coupling.

Since the earliest satellite in-situ observations were made at the magnetopause, it has been realized that the boundary position is constantly in motion, as evident by multiple magnetopause crossings in a single passage (Holzer et al., 1966; Cahill and Patel, 1967; Aubry et al., 1971). In many cases, detailed analysis of the magnetopause structures showed that the motion was caused by surface waves traveling tailward and causing ripples in the magnetopause (e.g. Aubry et al., 1971; Williams, 1979, 1980; Chen et al., 1993; Chen and Kivelson, 1993). In other cases, the shape of the magnetopause during a series of closely-spaced multiple crossings was close to the model boundary and thus was not caused by the passage of a surface wave, and it was suggested that multiple crossings were the result of oscillations in the erosion rate due to the time-varying reconnection at the magnetopause (Cahill and Skillman, 1977; Kaufmann and Cahill, 1977).

Several mechanisms have been identified in observations and theories as the driving sources for the magnetopause motion and coupled magnetospheric pulsations, including fluctuating solar wind dynamic pressure from various sources (e.g. Sibeck, 1989; Wright and Richard, 1995; Engebretson et al., 1998; Kepko et al., 2002), the Kelvin-Helmholz (K-H) instability (e.g. Southwood, 1968; Pu and Kivelson, 1983; Miura, 1992), and time-varying reconnection, such as pulsed reconnection and flux transfer events (FTEs) (e.g. Southwood, 1987; Glassmeier et al., 1984). The issue of which is the dominant mechanism remains one of the major controversies in magnetospheric studies (Lui, 2001).

The role of reconnection on the magnetopause oscillations and Pc5 pulsations is a subject of increasing debate, although there is general agreement that the momentum and energy transfer from the solar wind to the Earth's magnetosphere is controlled primarily by reconnection of the magnetospheric and magnetosheath magnetic fields at the Earth's magnetopause. Observations have shown that the reconnection process sometimes occurs in a quasi-continuous fashion but sometimes can be quite discontinuous, as with flux transfer events (FTEs). Even in quasi-continuous cases, reconnection appears to be a very dynamic process, as evident by pulsed, accelerated plasma jets near the magnetopause and the pulsed reconnection rate inferred from cusp plasma observations (Lockwood and Smith, 1992; Phan et al., 2001). There is no doubt that the reconnection process changes the magnetopause position since reconnection erodes the magnetic flux in the dayside magnetosphere and results earthward motion of the magnetopause, even when the solar wind dynamic pressure is unchanged (Petrinec and Russell, 1993).
A pulsed reconnection rate can cause the magnetopause to be oscillatory even if the reconnection process is continuous over an extended time period. When reconnection occurs in a time-varying fashion, as in FTEs, it produces a localized, moving open-flux tube, which compresses the neighboring plasma and magnetic field and causes a tailward traveling surface wave at the magnetopause as the flux tube moves tailward. The statistical recurrence rate of FTEs is within the Pc5 band (e.g. Kuo et al., 1995).

In a statistical survey using in-situ observations, Song et al. (1988) found that the magnetopause is more oscillatory under southward interplanetary magnetic field (IMF) conditions than under northward IMF conditions. The amplitude of the magnetopause oscillation increases with increasing angle from the Sun-Earth line only for southward IMF conditions, but not for northward IMF conditions. They suggested that the reconnection-related phenomena rather than the K-H instability play a major role in causing surface waves at the magnetopause under southward IMF conditions. For northward IMF conditions, they found that the motion of the magnetopause could be accounted for solely by the solar wind dynamic pressure fluctuations. In a separate statistical study on the role of the foreshock pressure fluctuations and the IMF direction in causing magnetopause motions, it was found that the IMF $\mathrm{B}_{z}$ component controls the magnetopause motion only in the afternoon side where it is free from foreshock effects (Russell et al., 1997). On the morning side the foreshock plays a significant role in controlling the magnetopause motion for both northward and southward IMF.

However, statistical studies using ground-based observations have long revealed a strong correlation between Pc5 pulsations and the solar wind speed, which can be readily explained by the K-H instability (e.g. Singer et al., 1977; Anderson et al., 1991; Miura, 1992; Engebretson et al., 1998). The magnetic field effect on the K-H instability also predicts that the pulsations are more likely to occur under northward IMF conditions and the wave power is higher in the dawn flank than in the dusk flank, which is indeed observed in a statistical sense. Nevertheless, a recent statistical study using 10-year's worth of CANOPUS data showed that the two classes of Pc5 pulsations, one that exhibits classic field line resonance (FLR) characteristics and one that does not, have different occurrence patterns (Baker et al., 2003). The K-H instability appears to be the primary driver for the FLR pulsations that occur at the flanks away from local noon with a dawn/dusk asymmetry and under high-speed solar wind conditions. But the K-H instability is unlikely to be responsible for the non-FLR pulsations that occur symmetrically about local noon and have an energy source at the magnetopause nose. This suggests that there are two source mechanisms for Pc5 pulsations. Even for the ground-based Pc5 waves associated with high-speed solar wind, the K-H instability is not the only mechanism at work, as suggested in the study by Kessel et al. (2004), who investigated the linkage of Pc5 wave power in the solar wind, magnetosheath, and on the ground during high-speed solar wind streams. They found a clear correlation between total Pc5 wave power outside and 
inside the magnetosphere. They suggested that the random boundary motion or surface waves associated with the compressional Pc5 wave power in the high-speed stream could be a source of magnetospheric Pc5 waves.

In recent years, several studies have been reported in the literature which used coordinated satellite in-situ observations of the magnetopause boundary layer and conjugate ground-based observations of Pc5 pulsations to understand their driving mechanisms. In some cases, reconnection was ruled out and it was concluded that the K-H instability was the most likely excitation mechanism (Sarafoupoulos et al., 2001; Mann et al, 2002; Pitout et al., 2003). The rationale to rule out reconnection is that these observations were either during northward IMF, which does not favor reconnection, or during high-speed solar wind which favors the K-H instability. Meanwhile, Pc5 pulsations were observed simultaneously in both the dawn and dusk flanks, a likely consequence of the K-H instability. But in other cases, the magnetopause oscillation and coupled ground Pc5 pulsations appeared to correlate with the IMF $\mathrm{B}_{z}$ variations in the Pc5 band, and thus, likely to be driven by pulsed reconnection at the magnetopause (Prikryl et al., 1998).

Previous studies clearly demonstrated that multiple mechanisms are at work on the magnetopause that drive the boundary motion and surface waves. Many questions remain unanswered such as whether there is a dominant mechanism or whether one mechanism will become dominant under certain conditions. Answering these questions requires coordinated in-situ and ground-based observations in key locations to understand every step of the solar wind-magnetosphereionosphere coupling process. This paper presents a detailed analysis of the structures of the magnetopause and adjacent magnetosphere observed by the Polar spacecraft, the dayside magnetosphere at geosynchronous orbit by the GOES spacecraft, and ground-based magnetic field by the CANOPUS and $210^{\circ}$ Magnetic Meridian (210 MM) magnetometer arrays during a high-speed solar wind stream on 7 February 2002. We present in-situ observations of the processes occurring at the magnetopause and vicinity, including surface waves, oscillatory magnetospheric magnetic field lines, and flux transfer events. In Sect. 2, we present an overview of the 7 February 2002 event. We then demonstrate that the Pc5 magnetospheric pulsations at geosychronous orbit and on the ground are directly driven by the oscillatory magnetopause (Sect. 3). We study the ground signature of the flux transfer events and its implication to the reconnection process (Sect. 4). We discuss the dominant mechanism responsible for the observed phenomena (Sect. 5). The data used in this study are from multiple instruments on board the Polar spacecraft including the Magnetic Field Experiment (MFE) (Russell et al., 1995), the Thermal Ion Dynamics Experiment (TIDE) (Moore et al., 1995) and the HYDRA instrument (Scudder et al., 1995), as well as the magnetometer data from the GOES 8 and 10 spacecrafts (Singer et al., 1996) and at the CANOPUS (Rostoker et al., 1995) and the $210 \mathrm{MM}$ (Yumoto et al., 1992; Yumoto et al., 2001) ground magnetometer arrays.

\section{Event overview}

The event of interest occurred in the latter part of the day on 7 February 2002 (21:00-24:00 UT) in the magnetosphere as observed by the Polar and GOES spacecraft, as well as ground-based observatories. The ACE and Wind spacecraft were in the solar wind with both the IMF and plasma data available during the interval of interest. The ACE spacecraft was near the L1 point, about $235 \mathrm{R}_{E}$ upstream from the center of the Earth and about $42 \mathrm{R}_{E}$ from the Sun-Earth line in the $-\mathrm{Y}$ direction. The Wind spacecraft was $\sim 315 \mathrm{R}_{E}$ from the Earth in the $-\mathrm{Y}$ direction and its $\mathrm{X}$ position was nearly zero. Figure 1 shows 20 days of hourly magnetic field in GSM and solar wind plasma data from ACE (red) and Wind (black), with 7 February shaded (no convection time delay is considered here). In general, both spacecraft observed the same large-scale heliospheric structure of high-speed solar wind streams, which commonly occur during the declining phase of the solar cycle. The data indicate that the event of interest occurred within a high-speed solar wind stream. The solar wind speed had increased to more than $600 \mathrm{~km} / \mathrm{s}$ on 6 February. During the time interval of interest from 21:00-24:00 UT on 7 February, the solar wind speed was $\sim 560 \mathrm{~km} / \mathrm{s}$. The solar wind dynamic pressure had a nominal value of $\sim 2 \mathrm{nPa}$.

Close examination of the high-resolution magnetic field data from ACE and Wind reveals that small-scale IMF features had very poor correlation at the two spacecraft. This is not surprising due to the large separation of the two spacecraft, especially in the Y-direction. Figure 2 shows $24 \mathrm{~h}$ of higher resolution (92s) IMF data in GSM from ACE (red) and Wind (black). The time has been shifted by $115 \mathrm{~min}$ from ACE to Wind, to match the large-scale structures. This time delay is much larger than the convection time delay from ACE to Wind, $\sim 44$ min, estimated from the solar wind speed and the spacecraft separation along the solar wind flow direction. The shaded region corresponds approximately to the time interval of interest in the magnetosphere (21:0024:00 UT), as estimated by the solar wind convection time delay from ACE to the magnetosphere, showing very poor correlation between the ACE and Wind IMF observations. At both spacecraft, the IMF $\mathrm{B}_{z}$ component fluctuated between north and south directions, but was southward on average for the whole interval of interest. Neither data set appeared to be a good representation of the near-Earth interplanetary conditions for the event, mainly because of the spacecraft's large distances from the Sun-Earth line. The Polar spacecraft entered the magnetosheath briefly during two intervals (22:09-22:10 and 23:18-23:19 UT), but we could not find an appropriate time delay from ACE to Polar so that there would be good correlations between the IMF clock angle and the magnetosheath magnetic field clock angle for both intervals. Based on the Polar data, the local magnetic field in the magnetosheath was southward for both intervals of brief magnetosheath excursions.

Figure 3 shows the spacecraft trajectories in the magnetosphere during the time of interest on 7 February 2002. The 


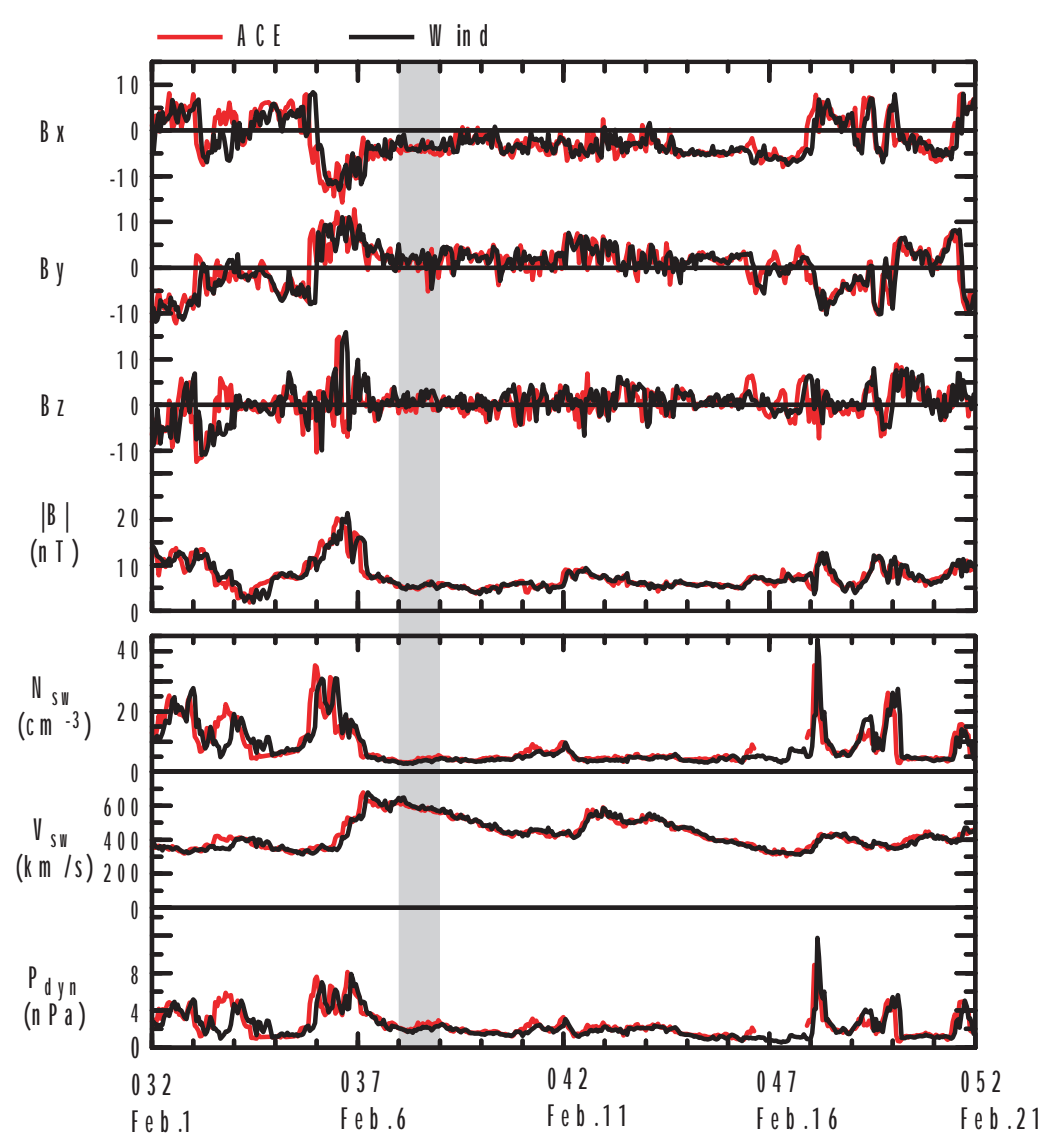

Fig. 1. Twenty days of hourly magnetic field and solar wind plasma data from ACE (red) and Wind (black), with the event day 7 February shaded.

left panel of Fig. 3 shows the orbits of Polar (blue), GOES 8 (red) and GOES 10 (green) projected in the GSM XY plane as viewed from the north. The time of interest is a 3-h interval from 21:00-24:00 UT on 7 February 2002, although a 13-h orbit segment for Polar is plotted. The Polar spacecraft moves from the Southern to the Northern Hemisphere with the orbit plane nearly in the 14:30 LT meridian plane (marked by the dashed line). The solid black trace is the model magnetopause from the Petrinec and Russell model (Petrinec and Russell, 1993) with a subsolar distance of $8.7 \mathrm{R}_{E}$, which is scaled by the average positions of the multiple magnetopause crossings observed by the Polar spacecraft (to be discussed in the next section). Thus, the size of the magnetopause appeared to be smaller than one would expect based on the nominal solar wind dynamic pressure of $\sim 2 \mathrm{nPa}$. In the right panel of Fig. 3, the Polar trajectory and the model magnetopause on the 14:30 LT meridian plane are shown. The solid symbols mark each 30-min interval along the trajectory during the time of interest, indicating that the Polar spacecraft was ideally skimming the vicinity of the magnetopause during this time interval.

The overview of the 3-h Polar observations is displayed in Fig. 4 showing, from top to bottom, the three components and the magnitude of the magnetic field data in GSM coordinates at 6-s time resolution, the HYDRA electron and ion energy spectrograms, and the TIDE ion energy and spin angle spectrograms, respectively. The HYDRA plasma data indicate that the spacecraft stayed inside the magnetopause in the magnetosphere for most of the time, as evident by the presence of hot magnetospheric electrons and ions with energy above $\sim 2 \mathrm{keV}$, except for a few short intervals of $\sim 1-$ 3 min with marked magnetic deflections that were accompanied by the presence of lower energy magnetosheath plasma (a few $10 \mathrm{~s} \mathrm{eV}$ to $\sim 1 \mathrm{keV}$ ) and the absence of hot magnetospheric plasma, especially hot electrons. These short intervals appeared to be either short excursions into the magnetosheath (22:09-22:10, 23:18-23:19), partial magnetopause crossings (21:19-21:20, 22:33-22:34) or flux transfer events (22:40-22:43, 22:54-22:57), and will be discussed in detail in the next sections. Starting from $\sim 21: 10$ UT, the magnetic field within the magnetosphere exhibits irregular fluctuations of $\sim 20 \mathrm{nT}$ with period of a few minutes in the Pc5 band. One notable feature in the TIDE data is the presence of cold dense ionospheric ions $(\sim 10-300 \mathrm{eV})$ occurring as quasi-periodic bursts with periods $\sim 6$ min throughout the interval, similar to the ionospheric ion flow bursts studied by Chen and Moore (2004). The TIDE spin angle spectrogram indicates that each cold ion burst was associated with a cycle of inward $\left(\sim 180^{\circ}\right.$ spin angle) then outward $\left(\sim 0^{\circ}\right.$ or $360^{\circ}$ spin angle) motion perpendicular to the magnetic field. 


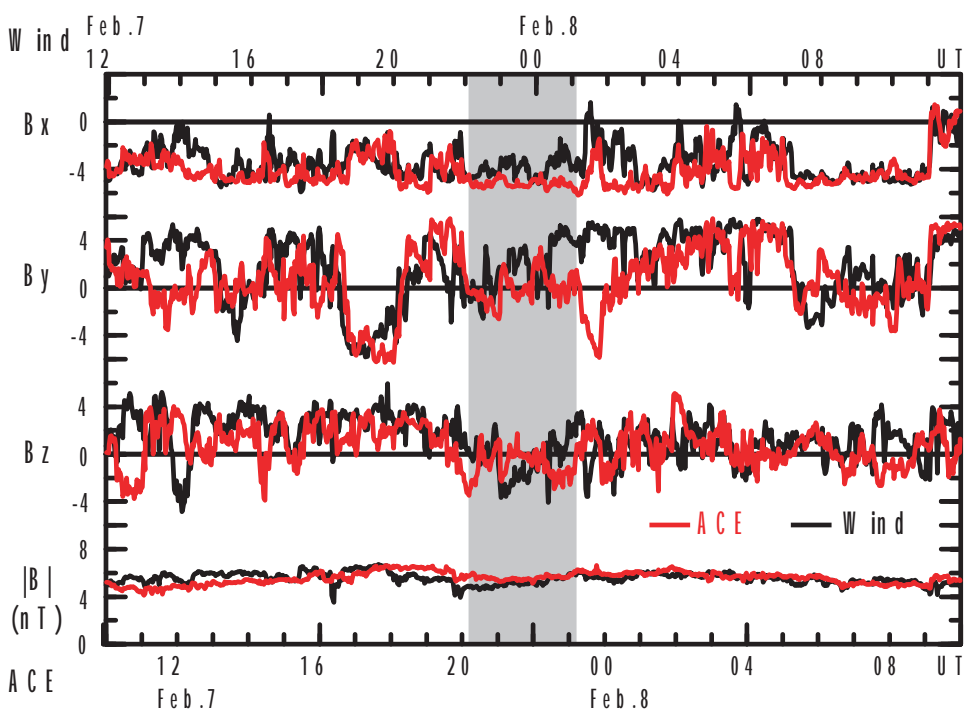

Fig. 2. High resolution IMF data from ACE (red) and Wind (black). The time has been shifted by 115 min to match the large-scale structures.
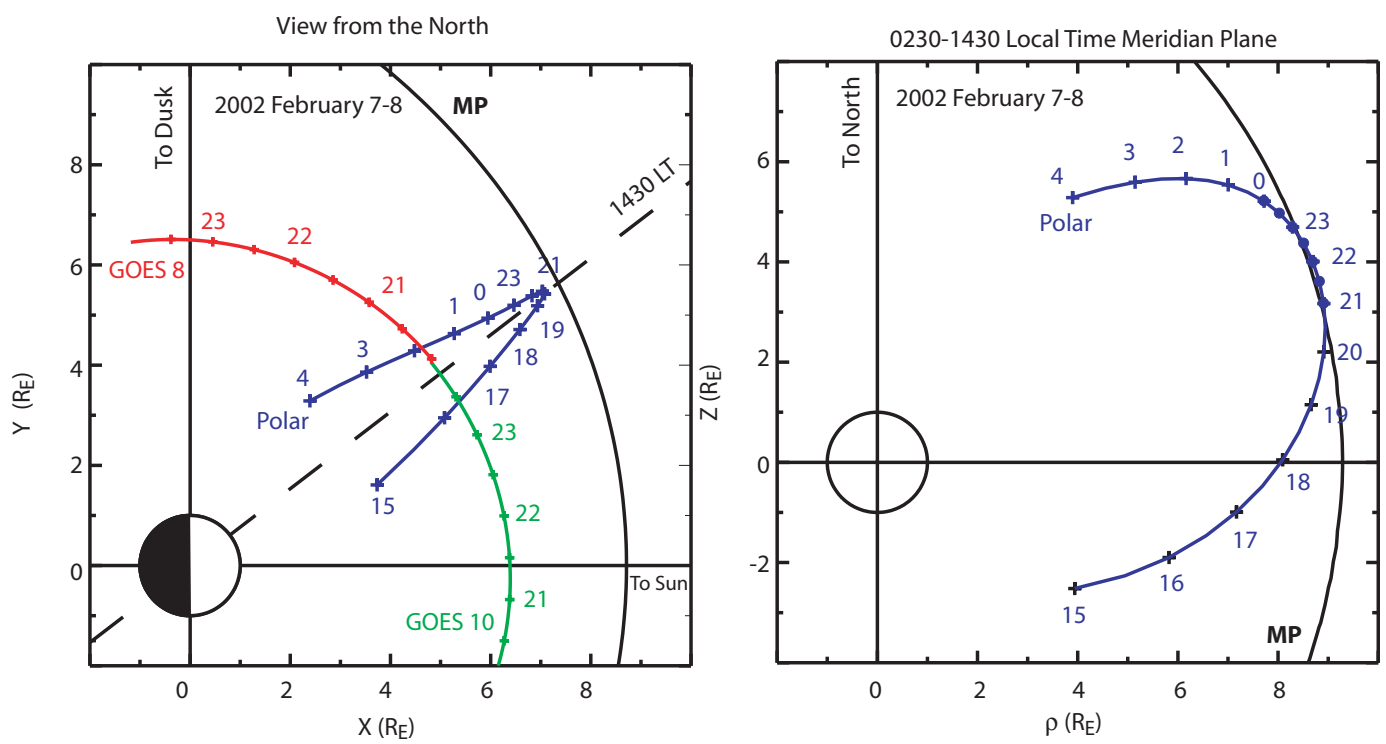

Fig. 3. Spacecraft trajectories in the magnetosphere during the time of interest on 7 February 2002. The left panel shows the model magnetopause (black) and orbits of Polar (blue), GOES 8 (red) and GOES 10 (green) projected in the GSM XY-plane as viewed from the north. The right panel shows the Polar trajectory and the model magnetopause in the 14:30 LT meridian plane. The solid symbols mark each 30-min interval along the trajectory during time of interest.

Since these dense cold ions are frozen in the closed magnetic flux tubes inside the magnetosphere, their velocity provides a good measure for the motion of the magnetopause boundary and the magnetic field lines just inside the magnetopause. The TIDE data show that the magnetic flux tube just inside the magnetopause was oscillating quasi-periodically at pe$\operatorname{riod} \sim 6 \mathrm{~min}$.

\section{Observations of Pc5 magnetic pulsations}

In this section, we present coordinated in-situ observations of oscillating magnetopause and magnetospheric magnetic pulsations at geosynchronous orbit and on the ground that are directly driven.

\subsection{Oscillating magnetopause and survace waves}

As shown in Fig. 4, several short intervals accompanied noticeable magnetic field deflections, both in magnetic field 

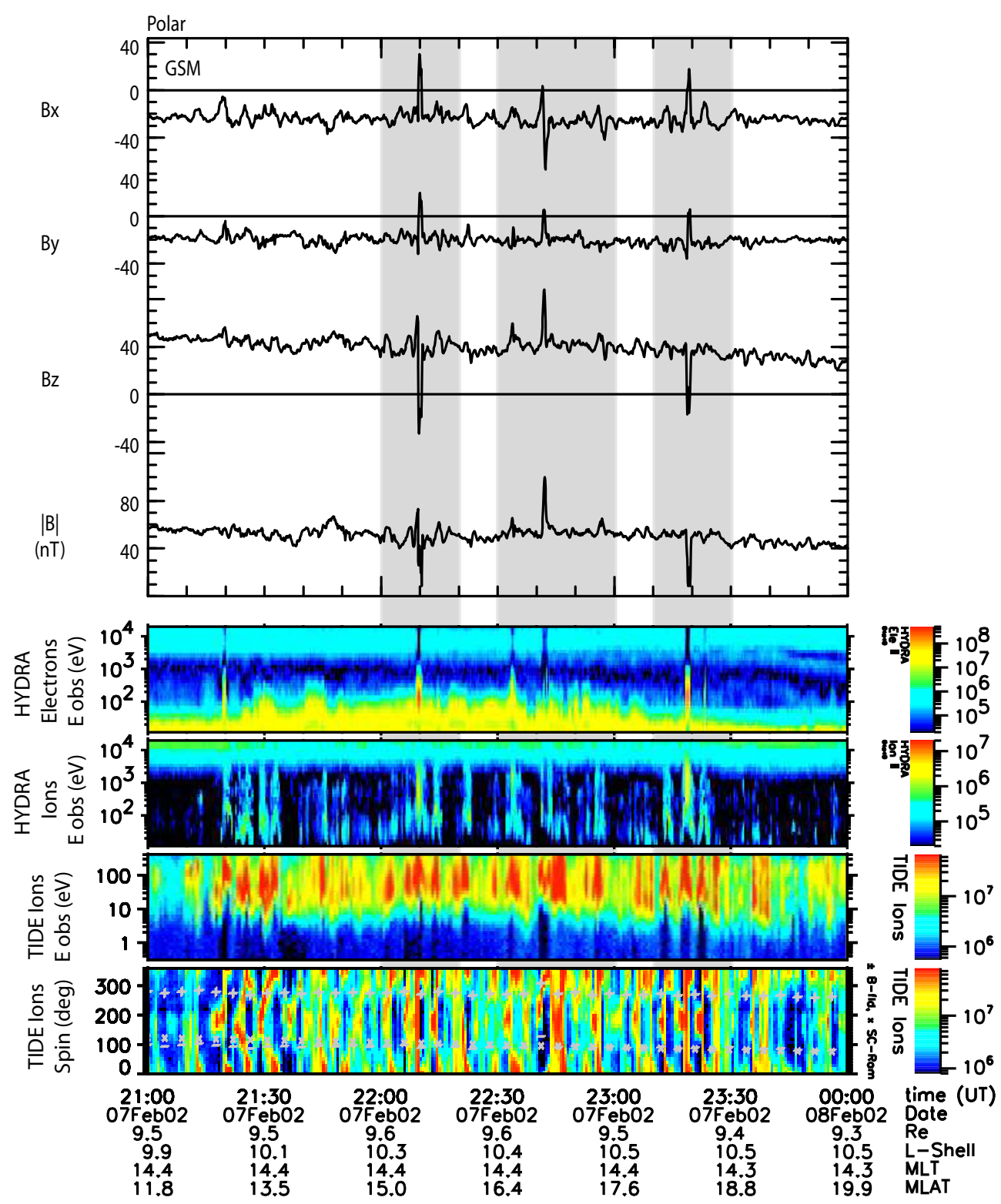

Fig. 4. A 3-h overview of Polar observations showing, from top to bottom, the three components and the magnitude of the magnetic field data in GSM at 6-s time resolution, the HYDRA electron and ion energy spectrograms, and the TIDE ion energy and spin angle spectrograms, respectively. The signs for flows parallel to the magnetic field direction (+), anti-parallel to the magnetic field direction (-), and opposite to the spacecraft motion direction $(\times)$ are overlaid in the TIDE spin angle spectrogram in the bottom panel. The spin angle of $270^{\circ}\left(90^{\circ}\right)$ corresponds to northward (southward) flow direction, and the spin angle of $180^{\circ}\left(0^{\circ}\right.$ or $\left.360^{\circ}\right)$ corresponds to earthward (sunward) flow direction.

components and in the field strength. Two of them, at 22:09-22:10 UT and 23:18-23:19 UT, appeared to be magnetosheath excursions of the Polar spacecraft, as the magnetic field turned southward and the magnetic field strength decreased within the magnetosheath. The details of the magnetopause crossings are shown in Figures $5 \mathrm{a}$ and 5b, respectively. Shown in Figs. 5a and b are, from top to bottom, the highest time resolution (8 samples/s) magnetic field data, the HYDRA ion and electron energy spectrograms, the TIDE ion energy and spin angle spectrograms, and the TIDE ion velocity moment data.
The TIDE data are the collapsed 3-D measurements of the cold plasma as 2-D velocity distributions in the spacecraft spin plane, which is nearly aligned with the meridian plane. A detailed description of the TIDE data can be found in Chen and Moore (2004). The ion velocity components $V_{x y}$ and $V_{z}$, shown in the bottom panels, are the spin plane velocity projected to the equatorial plane (nearly aligned to the radial direction) and along the Z-axis (north), respectively. They represent roughly the ion velocity perpendicular and parallel to the magnetic field, respectively. The positive (negative) $V_{x y}$ corresponds to the sunward (earthward) motion 


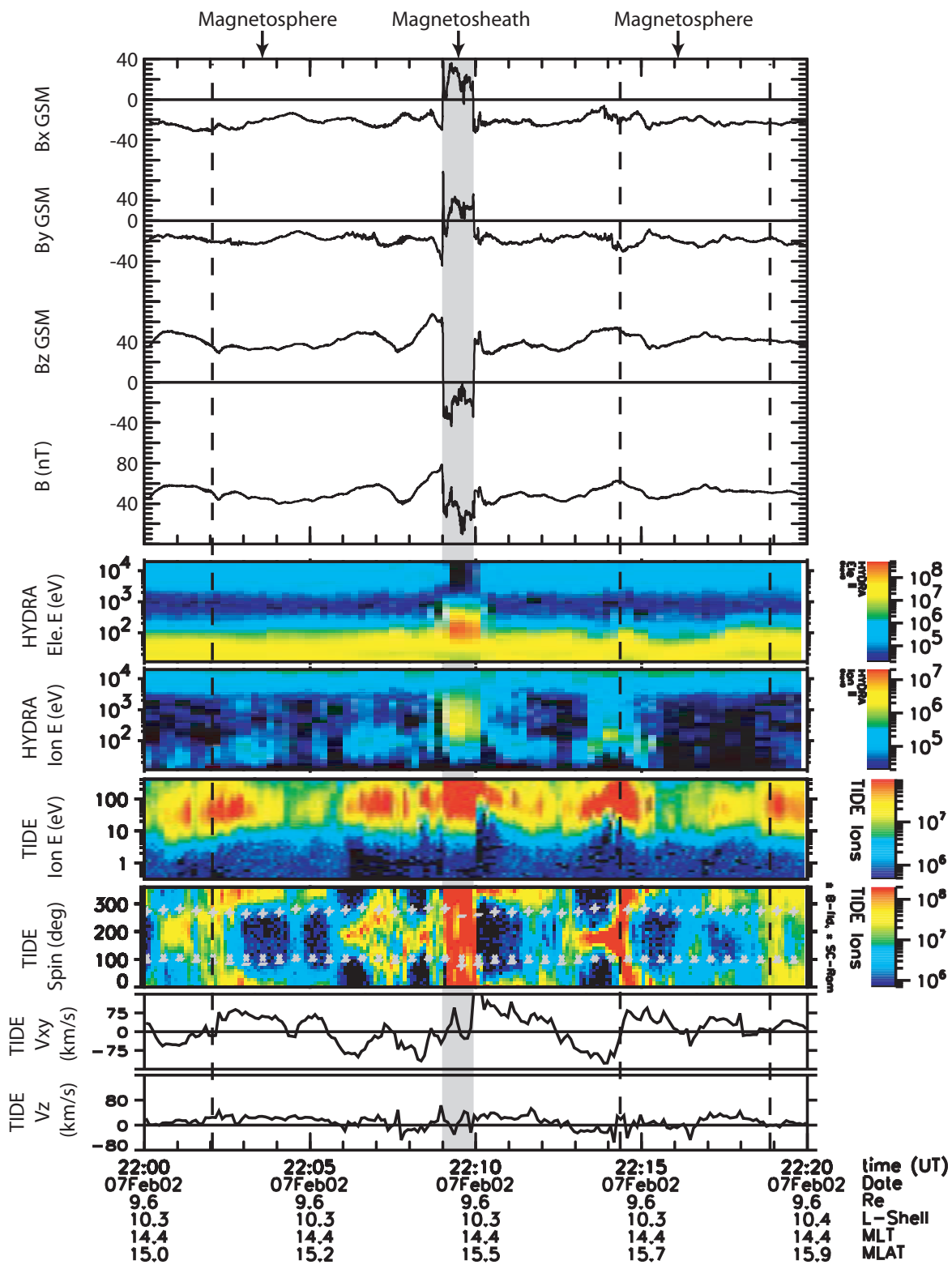

(a)

Fig. 5. Magnetopause crossings during the intervals (a) 22:00-22:20 UT and (b) 23:10-23:30 UT. Shown, from top to bottom, are the highest time resolution (8 samples/s) magnetic field data, the HYDRA ion and electron energy spectrograms, the TIDE ion energy and spin angle spectrograms, and the TIDE ion velocity moment data. The ion velocity components $V_{x y}$ and $V_{z}$ shown in the bottom panels are the spin plane velocity projected to the equatorial plane (nearly aligned to the radial direction) and along the Z-axis (north), respectively.

perpendicular to the magnetic field. The magnetosheath, marked by the shaded intervals, is characterized by the absence of hot magnetospheric plasma and the presence of magnetosheath plasma. The magnetosheath ions were seen in both the HYDRA and TIDE data, due to their large thermal spread from $\sim 10-1000 \mathrm{eV}$ and the overlap of the instruments' energy ranges.

The magnetopause current layer in Figs. $5 \mathrm{a}$ and $\mathrm{b}$ is characterized by sharp southward turnings in the magnetic field at the magnetosphere-magnetosheath transition, occurring at both edges of the shaded intervals. By performing the minimum variance analysis of the magnetic field data across both the outbound and inbound magnetopause current layer crossings, we find that the magnetopause boundary normal directions exhibited large deviations from the model normal direction in such a way that they were consistent with the passage of a tailward traveling surface wave, as illustrated in Fig. 6. The vector $\mathbf{n}_{\text {model }}$ is the boundary normal direction predicted by the Petrinec and Russell magnetopause model, projected in GSM XY plane. The dashed line is perpendicular to $\mathbf{n}_{\text {model }}$ and represents the local model magnetopause. The vectors $\mathbf{n}_{\text {out }}$ and $\mathbf{n}_{\text {in }}$ are the actual boundary normal 


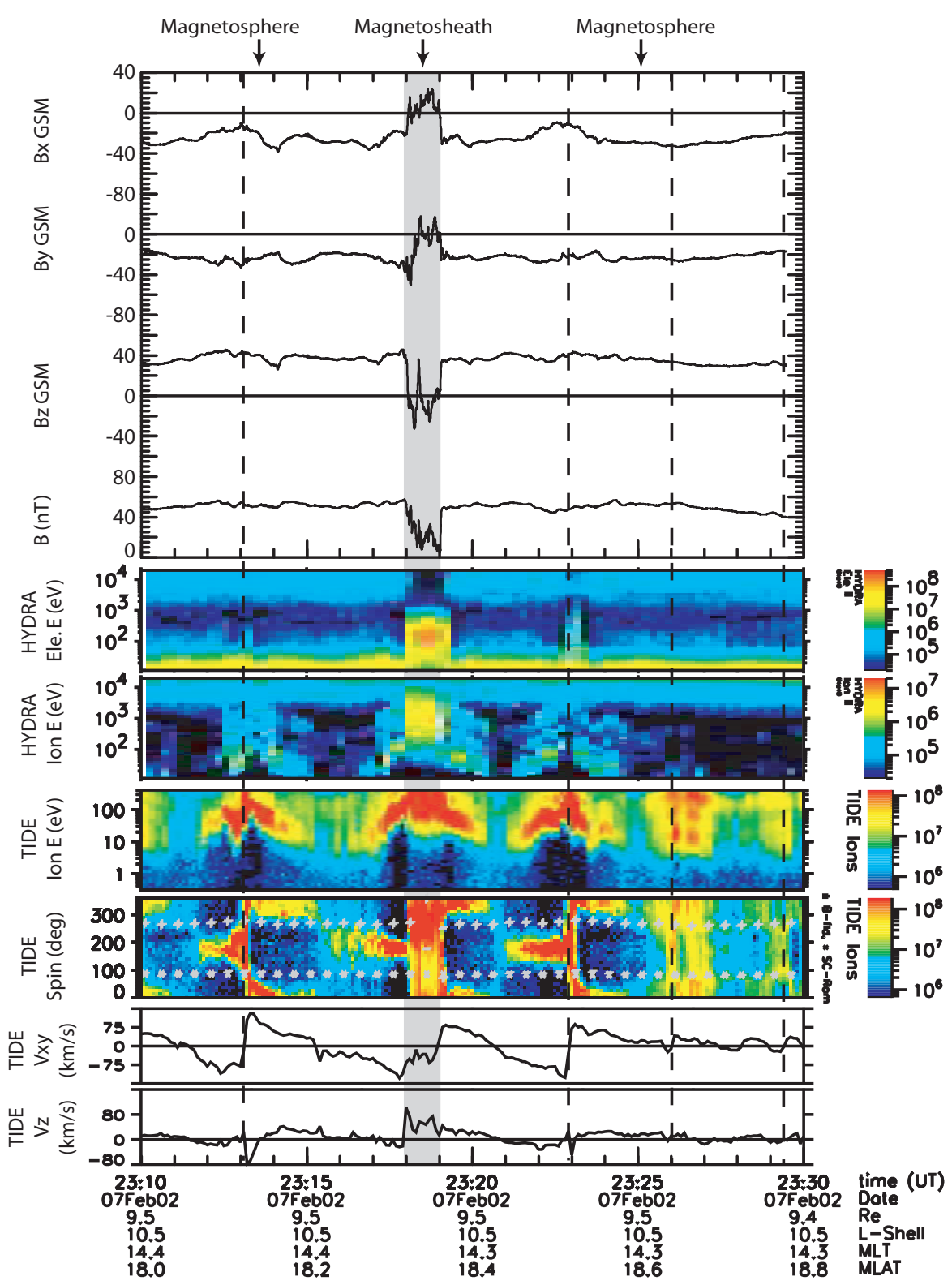

(b)

Fig. 5. Continued.

directions for the outbound and inbound magnetopause current layer crossings, respectively, obtained from the minimum variance analysis across the corresponding current layer. In each pair of the magnetopause crossings, the outbound crossing occurred first with $\mathbf{n}_{\text {out }}$ deflected dawnward from the model normal direction, and then the inbound crossing with $\mathbf{n}_{\text {in }}$ deflected duskward. Such a signature is as if an indention of the magnetopause position caused by a tailward traveling surface wave passes by the Polar spacecraft, as the solid curves schematically illustrate.

We have pointed out the quasi-periodic occurrence of the cold ion bursts observed inside the magnetosphere observed in the TIDE data in Fig. 4. Figures 5a and b also show more details of these cold, dense ion bursts (marked by dashed lines). These ions are of ionospheric source because of their narrow thermal spread from $\sim 10-100 \mathrm{eV}$, in contrast to those of the magnetosheath proper. They occurred every $\sim 6$ min throughout the interval when the spacecraft was near the magnetopause in its skimming orbit. During the magnetopause crossings in Figs. 5a and b, the cold ions occurred in the shell immediately earthward of the magnetopause current layer. For the outbound crossings, which indicate that the velocity of the local magnetopause has an earthward component as the surface wave was passing by, the motion of the cold ions was also moving earthward perpendicular to the magnetic field in the spacecraft orbit plane, as shown by their spin angle of $\sim 180^{\circ}$ and negative velocity component $V_{x y}$. For the two inbound crossings when the local 
magnetopause was moving sunward, so were the cold ions, as shown by a spin angle of $\sim 0^{\circ}$ or $360^{\circ}$ and positive velocity component $V_{x y}$. Thus, it is reasonable to believe that both the magnetopause and adjacent magnetospheric flux tube oscillated in phase in response to the surface wave. For all the other ion bursts observed (around the dashed lines) when the spacecraft did not encounter the magnetopause current layer, the ion spin angle showed the similar earthward-thensunward motion of the flux tubes, presumably in phase with the oscillating magnetopause, and the maximum velocity reached $\sim 130 \mathrm{~km} / \mathrm{s}$. The whole oscillating magnetopause interval lasted for $\sim 3 \mathrm{~h}$ at Polar, corresponding to the orbit segment when the spacecraft was skimming the magnetopause at $\sim 14: 30$ local time.

\subsection{Magnetic pulsations at geosynchronous orbit}

The Polar data have shown that the magnetopause and adjacent magnetospheric flux tubes were oscillating with an $\sim 6$ min period over an extended time period of $\sim 3 \mathrm{~h}$, apparently in response to the surface wave at the magnetopause. Thus, we examine the GOES magnetic field data in the dayside magnetosphere at geosynchronous orbit to determine the spatial extent of the oscillating magnetospheric field lines. For the time interval of interest, GOES 8 and 10 were in the dayside magnetosphere. Their orbits are shown in Fig. 3 as a red trace for GOES 8 and a green trace for GOES 10. The geosynchronous spacecraft were mainly in the post-noon quadrant. GOES 10 was near local noon moving duskward from $\sim 11$ to 14 local time. GOES 8 was moving duskward from $\sim 15$ to 18 local time.

In the left panel of Fig. 7, the GOES 8 and 10 magnetic field data at 1-min time resolution are shown for the time interval of interest. Their dynamic power spectra are shown in the right panels of Fig. 7. Both of the geosynchronous spacecraft observed magnetic pulsations in the Pc5 band, which appeared to be correlated to the oscillating magnetopause. First of all, the occurrence of the geosynchronous pulsations was coincident with the occurrence of the magnetic fluctuations near the magnetopause observed at Polar. The magnetic field fluctuations at Polar started at $\sim 21: 10$ UT. Accordingly, a noticeable onset of the geosynchronous pulsations occurred immediately after $\sim 21: 10$ UT, first at GOES 10 and then at GOES 8 a few minutes later. Secondly, the periods of the geosynchronous pulsations were consistent with the period of oscillating magnetopause of $\sim 6 \mathrm{~min}$. GOES 10 , which was in the subsolar region within $2 \mathrm{~h}$ of local noon, observed some low-frequency magnetic pulsations with a peakto-peak amplitude of a few $\mathrm{nT}$. The fluctuations were rather broad-banded in the range of $\sim 5-10 \mathrm{~min}$ with much reduced power. The magnetic pulsations observed by GOES 8 , which was a few hours away from local noon, were stronger and much more monochromatic. Their power spectrum was narrowly peaked at $2.8 \mathrm{mHz}$, or $6 \mathrm{~min}$ in period, which is similar to the period of the occurrence of the cold ion bursts and oscillating magnetic flux tubes observed near the magnetopause by Polar. Thus, strong geosynchronous pulsations

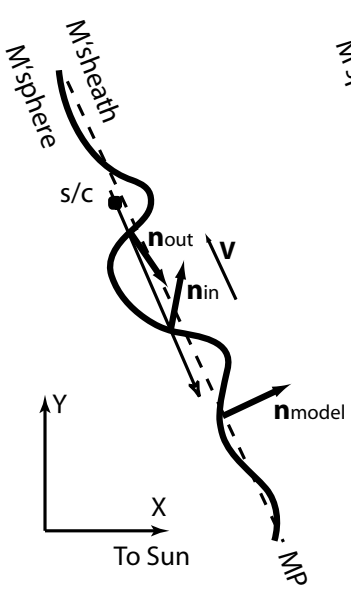

(a) 2208:53-2210:03 UT

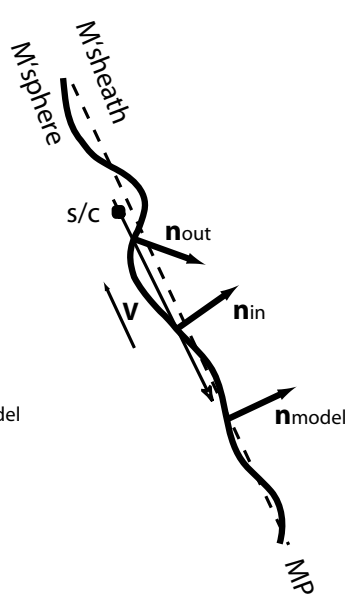

(b) 2317:55-2319:11 UT
Fig. 6. Surface waves at the magnetopause inferred from the magnetopause crossings. The dashed line and $\mathbf{n}_{\text {model }}$ are the local magnetopause and boundary normal direction predicted by the Petrinec and Russell magnetopause model. The vectors $\mathbf{n}_{\text {out }}$ and $\mathbf{n}_{\text {in }}$ are the actual boundary normal directions for the outbound and inbound magnetopause current layer crossings, respectively, obtained from the minimum variance analysis. The solid curve illustrates schematically the surface wave at the magnetopause.

occurred only in the limited local time range in the dayside post-noon sector. They were weak near local noon, and they do not appear to continue into the nightside, either. The strongest pulsations at GOES 8 were observed from $\sim 21: 10$ to 22:50 UT, or $\sim 15: 55-17: 35 \mathrm{LT}$.

\subsection{Magnetic pulsations on the ground}

Next we examine coordinated ground-based magnetometer data to determine how the waves at the magnetopause are coupled into the magnetosphere and the ionosphere. During the time of the event, the footprints of the Polar spacecraft were in the same local time and latitudinal region as the CANOPUS magnetometer array. Meanwhile, the 210MM array provided simultaneous observations in the morning sector. Figure 8 shows the geographical locations of the ground stations (squares) and spacecraft footprints (dots). In the North American sector, the ground stations include 11 CANOPUS stations at high latitudes and two from the UCLA magnetometer array at mid-latitudes: one at Los Alamos National Laboratory (LANL) and the other at San Gabriel Dam (SGD) near Los Angeles. The green and red dots are the footprints of GOES 10 and 8 spacecraft, respectively. The connected blue dots are the 4-h ground track of the Polar spacecraft from 20:00 to 24:00 UT, moving westward and marked every $30 \mathrm{~min}$. In the Asian/Pacific sector, 8 ground stations from the $210 \mathrm{MM}$ array are shown.

In Fig. 9, the ground stations and spacecraft footprints in the North American sector are shown in the Corrected GeoMagnetic (CGM) coordinates. The spacecraft footprints are determined by tracing the Tsyganenko 1996 magnetic field 

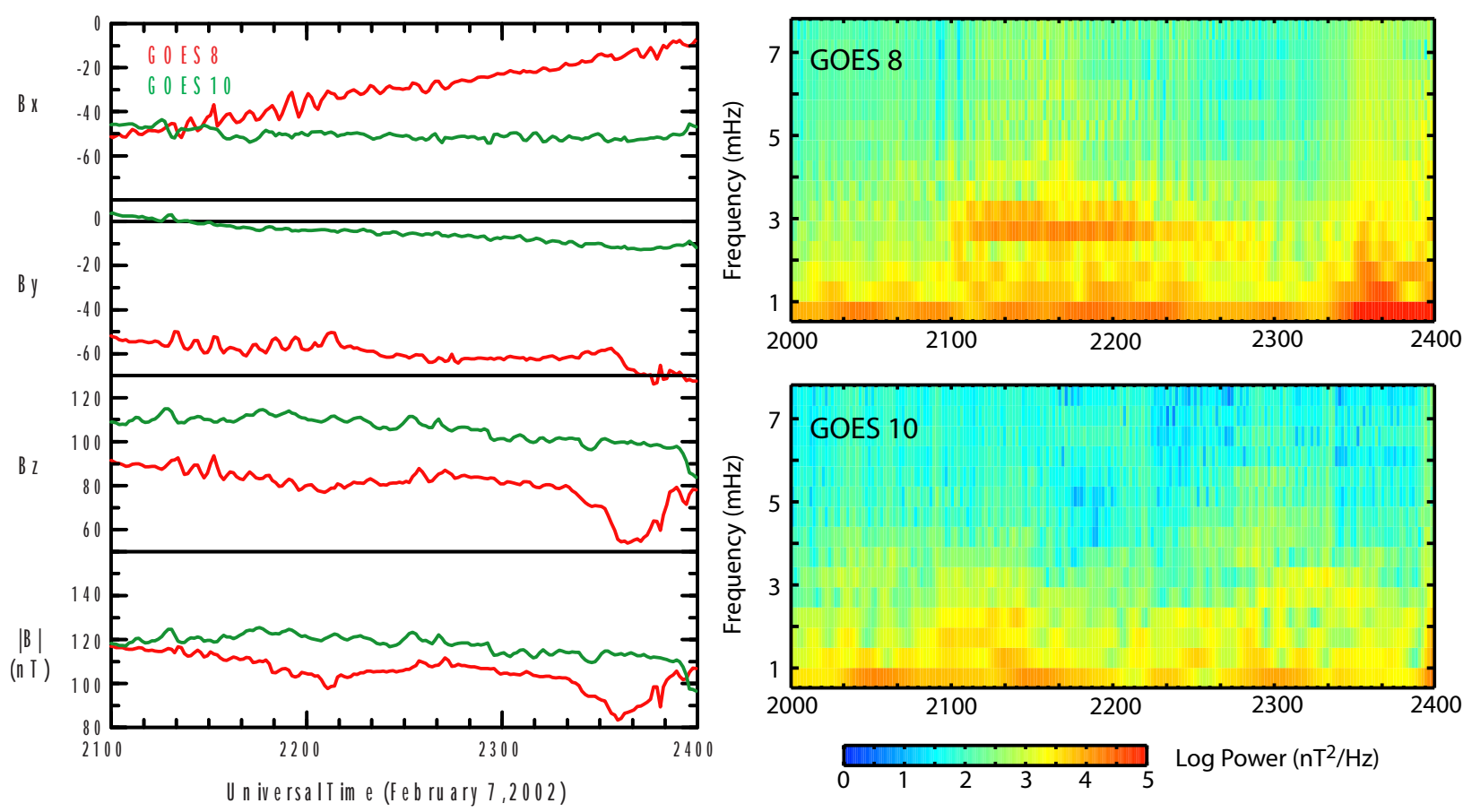

Fig. 7. The GOES 8 and 10 magnetic field data at 1-min time resolution (left panel) and their dynamic power spectra (right panels). The color bar shows the total power of the three components of the magnetic field in logarithm scale.

model under nominal solar wind conditions. For this event, the magnetopause standoff distance is found to be smaller than its nominal value, thus, the actual Polar footprints may be slightly higher in latitude. Since the Polar spacecraft was skimming the magnetopause during the interval of interest, its footprints are expected to be very close to the open-closed field line boundary.

The station TALO was clearly on the open field line that maps to the tail lobe. The station RANK is expected to be near or below the open-closed field boundary. All the other stations are expected to be on closed magnetospheric field lines.

The stacked horizontal components $(H$ and $D)$ of the magnetic field from the stations in the North American sector are shown in Fig. 10 for a 4-h period from 20:00 to 24:00 UT. In each right panel, the numbers next to the station name give the CGM latitude and longitude of the station. The top 6 panels correspond to those stations along the Churchill meridional line of the CANOPUS array, arranged from high to low latitudes. The next 5 panels are for stations in the east-west line, arranged by their longitudinal distance from the Churchill line. The bottom two panels are for the two mid-latitude UCLA stations. The vertical scale of each panel is $200 \mathrm{nT}$. The two vertical dashed lines mark the interval between 21:10 UT and 23:30 UT, the time when the oscillating magnetopause and geosynchronous magnetic pulsations were observed. As evident in Fig. 10, geomagnetic pulsations are seen at some CANOPUS stations that appear to be correlated.
Along the Churchill meridional line, strong geomagnetic pulsations with a peak-to-peak amplitude of $\sim 100 \mathrm{nT}$ can be easily seen in four stations, RANK, ESKI, FCHU and GILL, and their occurrence characteristics are very similar to that of the geosynchronous pulsations at GOES-8, whose footprint is $\sim 25^{\circ}$ (or $\sim 01: 40$ in local time) eastward from the line. In Fig. 11a, we show the stack plots of power spectra for all 6 stations along the meridional line, from high to low latitudes. Note each spectrum has a different baseline as the color-coded dashed lines indicate. To compare with the magnetopause oscillation and geosynchronous pulsations, the power spectra of GOES 8 and GOES 10 magnetic field data and the Polar TIDE ion velocity moment data $\left(V_{x y}\right)$ are also shown in Fig. 11.

Multiple spectral peaks are apparent at most stations along the meridional line. Of special interest is the peak at $2.7 \mathrm{mHz}$, which appears at all the spectra across the magnetosphere from the magnetopause, to geosynchrosnous orbit, to the ground stations. The pulsations at FCHU and GILL are dominated by waves at this frequency. However, the strongest spectral power at this frequency occurred only at 4 stations, all within $\sim 6^{\circ}$ in latitude below the openclosed field line boundary, namely RANK, ESKI, FCHU and GILL. The power of the spectral peak at $2.7 \mathrm{mHz}$ is one order of magnitude smaller at TALO, the station on open field lines, and about two orders of magnitude smaller at PINA, the station with the lowest latitude $\left(60.4^{\circ}\right.$, or $12^{\circ}$ below the open-closed field line boundary). Thus, strong pulsations only occur at limited latitudes that map to the magnetopause and outer magnetosphere. This is supported by 


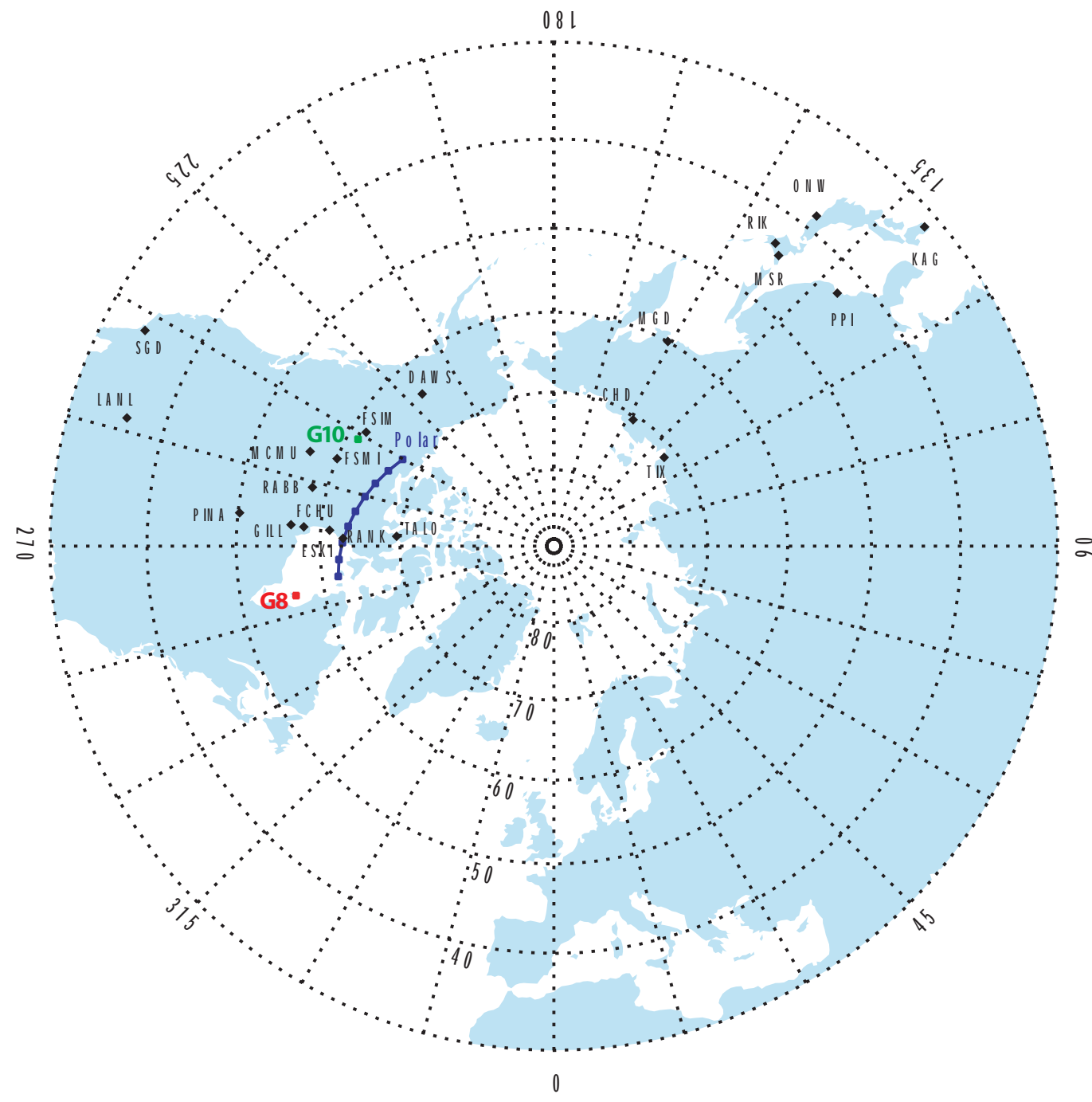

Fig. 8. Geographical locations of the ground stations (solid squares) and spacecraft footprints (dots). In the North American sector, the ground stations include 11 CANOPUS stations at high latitudes and two from the UCLA magnetometer array at mid-latitudes. The green and red crosses are the footprints of GOES 10 and 8 spacecraft, respectively. The connected blue dots are the 4-h ground track of the Polar spacecraft from 20:00 to 24:00 UT, moving westward and marked every $30 \mathrm{~min}$. In the Asian/Pacific sector, 8 ground stations from the $210 \mathrm{MM}$ array are shown.

the magnetograms of the two mid-latitude stations (two bottom panels of Fig. 10), in which we see little evidence of Pc5 pulsations. These observations suggest that the magnetic pulsations are directly driven by the oscillation of the magnetopause and adjacent flux tubes in the magnetosphere.

The stack plots of power spectra for the stations along the east-west line of the CANOPUS array are shown in Fig. 11b, arranged by the longitudinal distance from the Churchill line. The spectrum on the top is for station FCHU, a station in the Churchill line. In comparison, the power of the spectral peak at $2.7 \mathrm{mHz}$ decreases with increasing longitudinal separation from the Churchill line. The three closest stations, RABB, MCMU, and FSMI, all exhibit a similar narrow spectral peak at $\sim 2.7 \mathrm{mHz}$, and the same onset time and duration for the pulsations, but the spectral power is much reduced at MCMU, presumably due to its larger latitudinal distance from the open-closed field line boundary $\left(\sim 8^{\circ}\right)$. The stations FSIM and DAWS have the largest longitudinal separation from the Churchill line. They are located westward of the footprint of GOES 10, and so were near local noon during the event. Their spectra seem to be dominated by other unrelated pulsations, consistent with GOES 10 observations. At DAWS, the dominant pulsation had lower frequency and was present even before the event onset time of $\sim 21: 10 \mathrm{UT}$.

The coordinated spacecraft and CANOPUS observations presented so far suggest that the correlated pulsations in space and on the ground occur only in a localized region limited both in latitude and local time. The strongest pulsations directly driven by the oscillating magnetopause are limited within $\sim 6^{\circ}$ from the open-closed field line boundary, and within a longitudinal range from station $\mathrm{RABB}$ to the footprint of GOES 8. For the event interval of 21:10-23:30 UT, 
the combined local time range is $\sim 4 \mathrm{~h}$, from $\sim 14: 00-18: 00$ local time. To confirm that the pulsations indeed occur in this limited local time region, we examine simultaneous groundbased magnetic field observations from the $210 \mathrm{MM}$ array in the morning sector, as shown in Fig. 12. The CGM latitudes of stations TIX and CHD are similar to that of MCMU and higher than that of PINA, but for the event interval, there is little evidence of coincidental pulsations that are related to those in the post-noon sector. The observations at midlatitude stations do not show any Pc5 pulsations in the morning sector. Instead, strong Pc3 pulsations are present.

\section{Observations of flux transfer events and their foot- prints}

\subsection{Flux transfer events at the magnetopause}

We have shown in Fig. 4 that Polar observed a very strong flux transfer event in the magnetosphere occurring at 22:4022:43 UT. This event had the classical FTE signature, which was distinctly different from those of the magnetosheath excursions at 22:09-22:10 UT and 23:18-23:19 UT presented in Sect. 3.1. The strong bi-polar signature was mainly in the $\mathrm{X}$-component in GSM. To display the data in boundary normal coordinates, we found that the model boundary normal direction did not agree with the instantaneous local boundary normal direction, which is not surprising due to the presence of surface waves on the magnetopause. The local boundary normal direction at the FTE is found to be deflected $\sim 37^{\circ}$, mainly dawnward, from the model boundary normal direction. Figure 13 shows highest resolution magnetic field data and plasma data from 22:30 to 23:00 UT. The figure is in the same format as Figs. 5a and b except that the magnetic field data here are displayed in the local boundary normal coordinates. The FTE at 22:40-22:43 UT had a very strong bi-polar magnetic field signature of $\sim 80 \mathrm{nT}$ peak-to-peak in the boundary normal direction. It also had a very strong core field, which at peak is substantially enhanced to about two times the $\sim 47 \mathrm{nT}$ average magnetospheric field. Thus, the observed FTE has a flux rope structure with a helical magnetic field inside the core. The observed strong core field combined with the characteristic bi-polar signature strongly argues that it is a reconnection-related phenomenon. It is very unlikely that such a strong core field could be produced by any process other than reconnection, such as magnetosphere compression due to a pressure enhancement in the solar wind.

The HYDRA plasma spectrograms within the core of the FTE show that the magnetospheric hot electrons were almost completely depleted, which is an indication of open flux tube configuration, but the magnetospheric hot ions were only slightly depleted. Meanwhile, the cold ions of ionospheric source are present, but there is very little evidence of the presence of magnetosheath plasma inside the FTE. These observations suggest that the FTE flux rope was just formed a

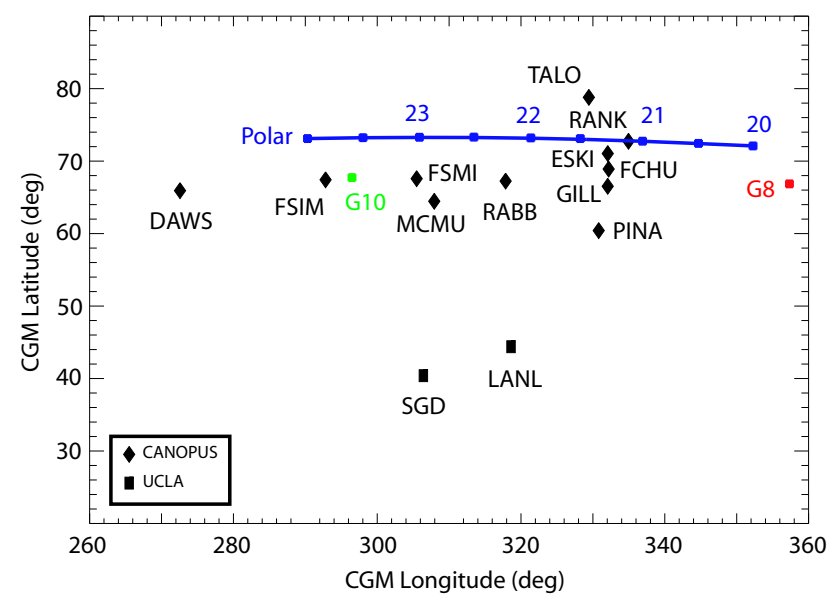

Fig. 9. The ground stations and spacecraft footprints in the North American sector in the Corrected GeoMagnetic (CGM) coordinates.

short time ago, so that only the hot magnetospheric electrons had time to escape since they are the most mobile species.

The plasma data suggest that this FTE was observed very close to the magnetopause boundary, thus the spacecraft passed through the core of the flux rope. Actually, the spacecraft had just made a partial crossing of the magnetopause at 22:33-22:34 UT due to the oscillating magnetopause, as evident by the enhanced flux of the magnetosheath plasma, and earthward-then-sunward motion of the cold ionospheric ions. There was apparently another FTE observed at 22:5422:57 UT. This one had a typical bi-polar magnetic signature, but there was no evidence of escaping magnetospheric hot plasma from the flux tube. Thus, it is more likely that Polar did not encounter the core of the FTE flux rope, instead it was in the draping region outside the open flux rope where the magnetic field was compressed but remained closed with both ends connected to the ionosphere. This could happen when the distance between the spacecraft and the instantaneous magnetopause was greater than the cross-section size of the FTE flux rope in the boundary normal direction, typically $\sim 1 \mathrm{R}_{E}$ (Saunders et al., 1984).

\subsection{FTE footprints on the ground}

Since the first observations of flux transfer events in the spacecraft data (Russell and Elphic, 1978), it has been of great interest to identify their possible ionospheric footprints in ground-based observations. Theories predict that the convection of the FTE flux tube generates an Alfvén wave within the flux tube, which carries a helical magnetic field and a pair of field-aligned currents from the magnetopause to the ionosphere (Cowley, 1982; Saunders et al., 1984; Southwood, 1987). The closure of the field-aligned currents is through Pedersen currents, and the associated electric field drives a Hall current (Southwood, 1987). The ground magnetic fields produced by the field-aligned currents and Pedersen current cancel each other, and the ground signatures of flux transfer events are expected to be transient magnetic perturbations 
H-component

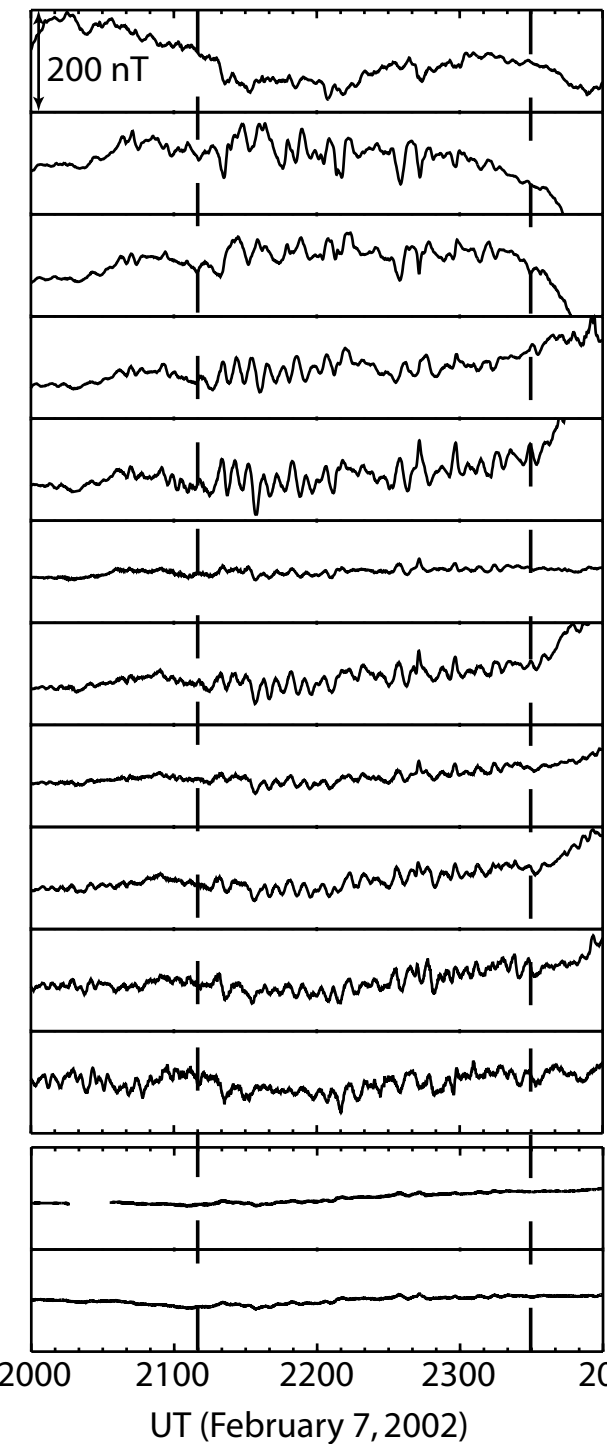

D-component

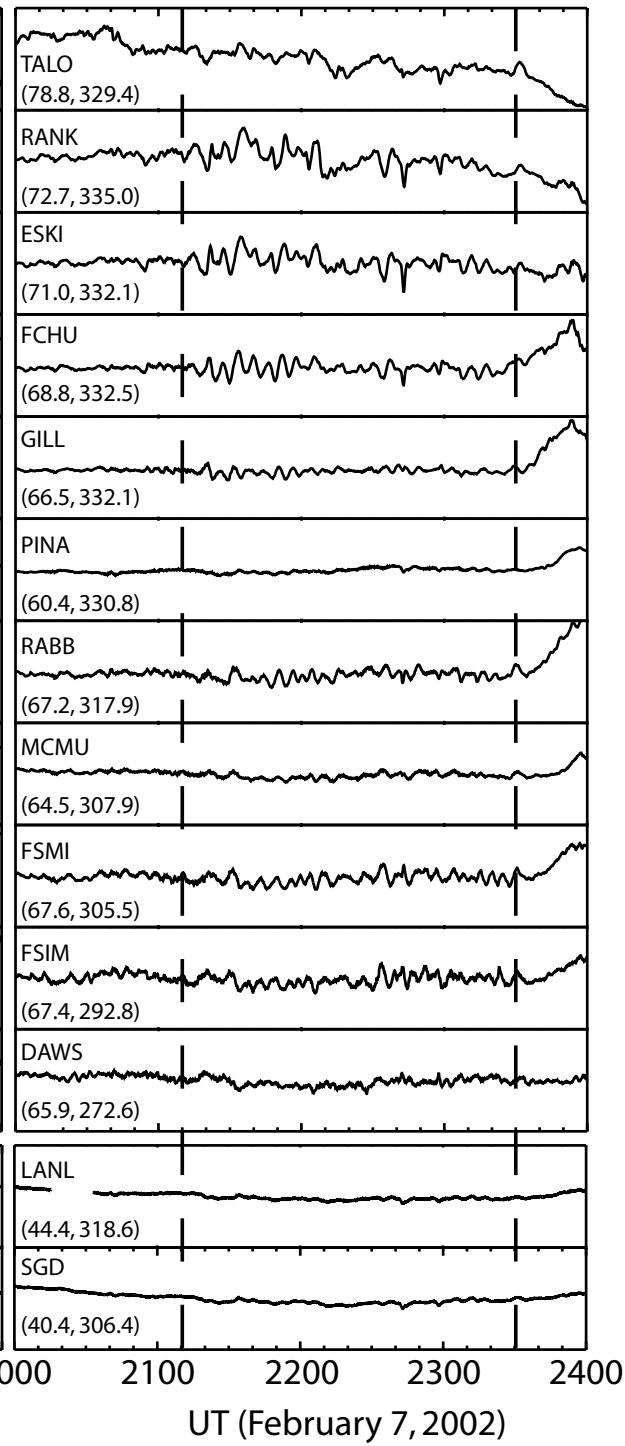

Fig. 10. The stacked horizontal components $(H$ and $D)$ of the magnetic field from the stations in the North American sector for a 4-h period from 20:00 to 24:00 UT. In each right panel, the numbers next to the station name give the CGM latitude and longitude of the station.

at the footprints associated with Hall current flowing in the ionosphere (Lanzerotti et al., 1986; McHenry and Clauer, 1987; Wei and Lee, 1990; Chaston et al., 1993).

Several theoretical works have been performed to model the ground magnetic signatures associated with traveling field-aligned current systems of FTEs (McHenry and Clauer, 1987; Wei and Lee, 1990; Chaston et al., 1993). In all these models, the initial FTE open flux tube maps to a circular cross section in the ionosphere as reconnection occurs only in a localized patch on the magnetopause. These models consider the motion and evolution of the flux tube footprint and current system in the polar ionosphere and predict that magnetic disturbances are present in all three components of the geomagnetic field. However, the details of the predicted magnetic disturbances vary significantly with different models due to the different moving path of the flux tube and evolving current systems in the model. For example, the magnetic disturbance exhibits a bi-polar signature in the north-south component and a unipolar signature in the east-west and vertical components in McHenry and Clauer (1987). In Chaston et al. (1993), the magnetic disturbances are more complicated varying from bi-polar, unbalanced bi-polar, to unipolar forms in all three components depending on the ground station's relative location to the flux tube footprint. In all the models, the predicted magnetic signatures are traveling disturbances with a speed in the range of $0.5-3 \mathrm{~km} / \mathrm{s}$, and thus are best detected using an array of ground magnetic stations. Based on a $\sim 20-n T$ detection limit, these models predicted a detection range of $\sim 600 \mathrm{~km}$ in the ionosphere.

The search for FTE signatures in ground magnetic field data has not provided unambiguous results due to the lack 
(a) CANOPUS Churchill Line

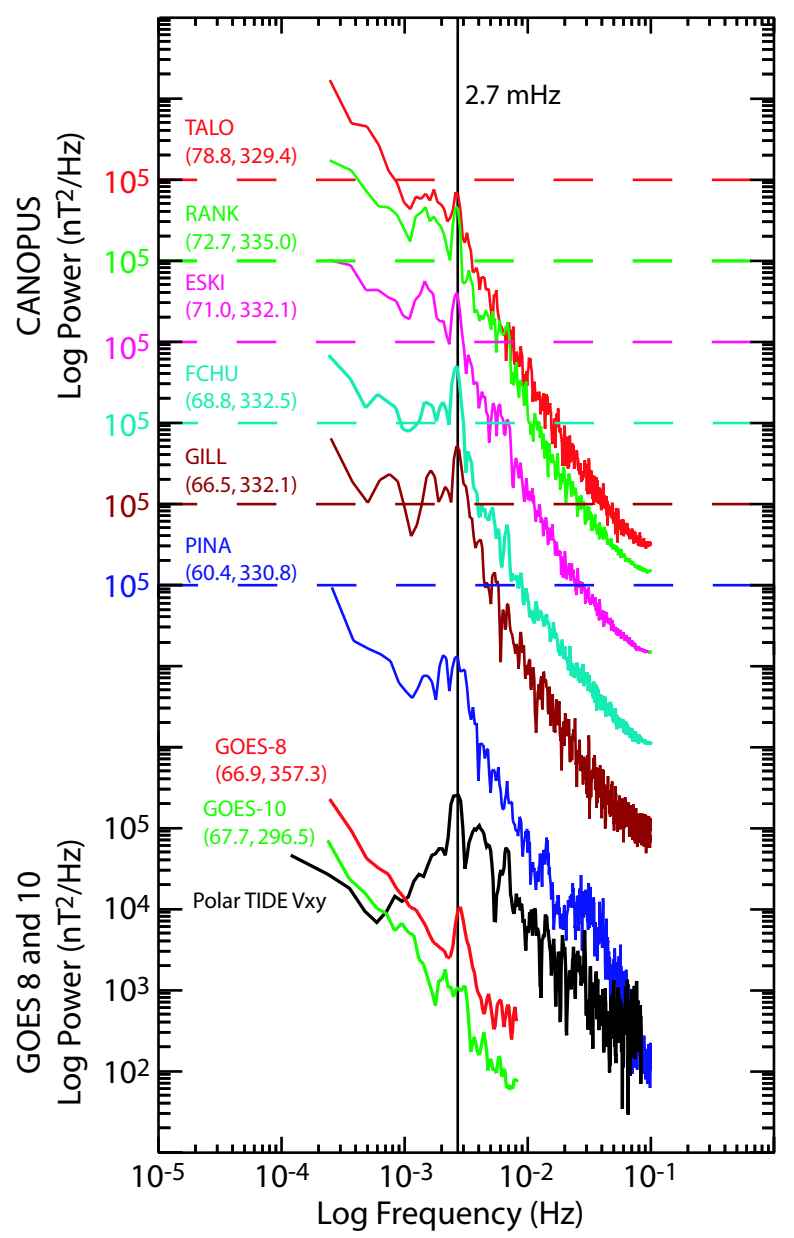

(b) CANOPUS East-West Line

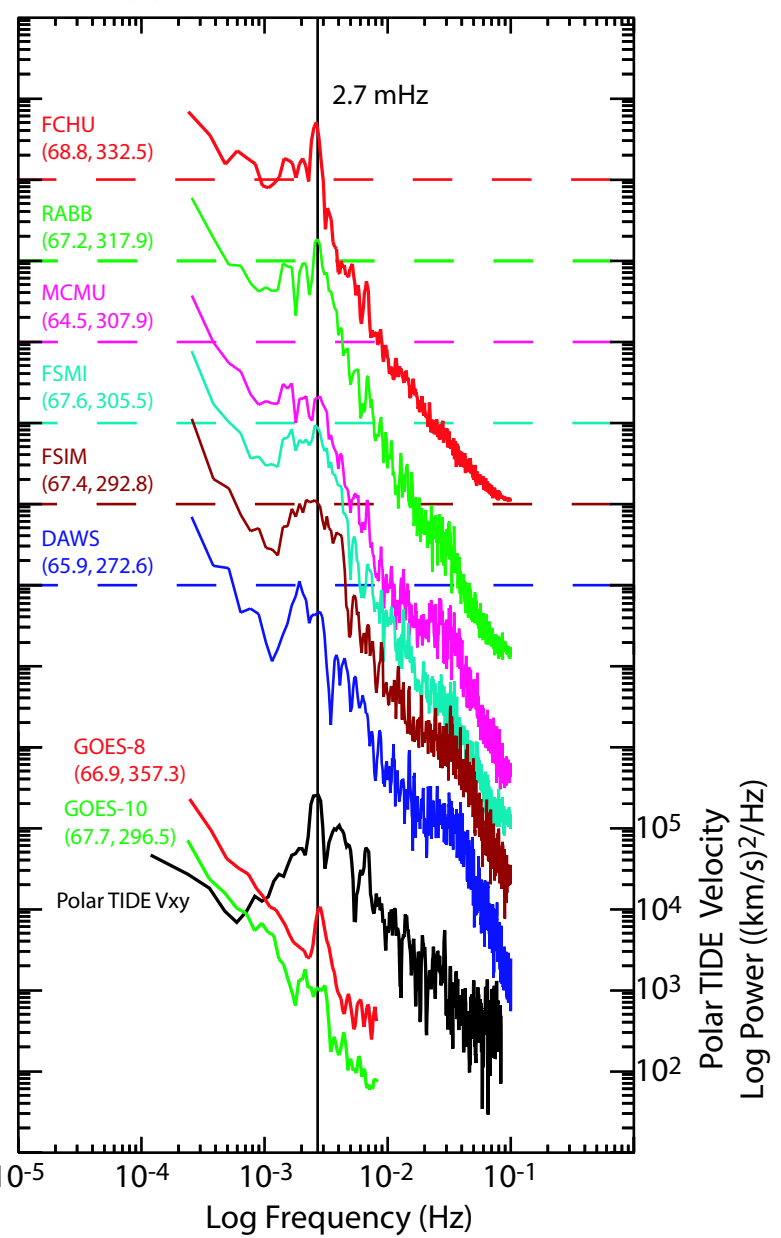

Fig. 11. Stack plots of power spectra for the CANOPUS magnetic field, GOES 8 and 10 magnetic field, and the Polar TIDE ion velocity moment $\left(V_{x y}\right)$. Note the power spectra of the CANOPUS stations have different baselines as indicated by the color-coded dashed lines. (a) Stations along the Churchill line. (b) Stations along the east-west line.

of direct correlation of FTE on the magnetopause and transient signature on the ground (Glassmeier and Stellmacher, 1996). The ground observations were made either at a different local time from the in-situ observation (Glassmeier et al., 1984; Elphic et al., 1990), or when there was a lack of in-situ observations (Goertz et al., 1985; Lanzerotti et al., 1986; Sandholt et al., 1992). More recently, a few cases of spacecraft-ground conjunctions were published to report the ionospheric flow response to FTEs (Neudegg et al., 1999, 2001; Wild et al., 2001), which show more conclusively that enhanced ionospheric flow is associated with the FTE at the expected position of the field-aligned current in the FTE.

In this paper, we present direct evidence of transient magnetic disturbances at the footprint of the FTE flux tube. Two flux transfer events were observed by Polar near the magnetopause at 22:40-22:43 and 22:54-22:57 UT. A close examination of the CANOPUS data in Fig. 10 at the FTE occurrence times reveals that coincident transient magnetic perturbations are indeed evident at all stations except TALO (the station which maps to the tail lobe) and DAWS (the most westward station).
The ground magnetic field signatures associated with the FTEs appear to be a transient unipolar perturbation superposed on top of the Pc5 pulsations discussed in Sect. 3.3. Figure 14 shows an expanded view of the CANOPUS magnetic field data as well as the simultaneous Polar $\mathrm{B}_{x}$-component in GSM and the field strength. The two dashed lines mark the central cores of the two flux transfer events. The CANOPUS data are arranged by the stations' magnetic latitudes, from high to low. The FTE ground signatures occurred with a time delay of $\sim 1$ min from the Polar observations. They appeared in the $H$-component from most stations, except FCHU, as southward unipolar perturbations at stations above FCHU latitude and northward unipolar perturbations below FCHU. The FTE ground signatures in the D-component appeared as a westward perturbation and were strongest in the higher latitude stations. In the $Z$-component, negative perturbations were apparent only in stations along the Churchill line. The amplitudes of the FTE ground perturbations are in the range of $\sim 15-70 \mathrm{nT}$, similar to the range predicted by the models discussed earlier. But the detection range spans over $\sim 42^{\circ}$ in longitude, or a longitudinal distance of $\sim 1700 \mathrm{~km}$, which 


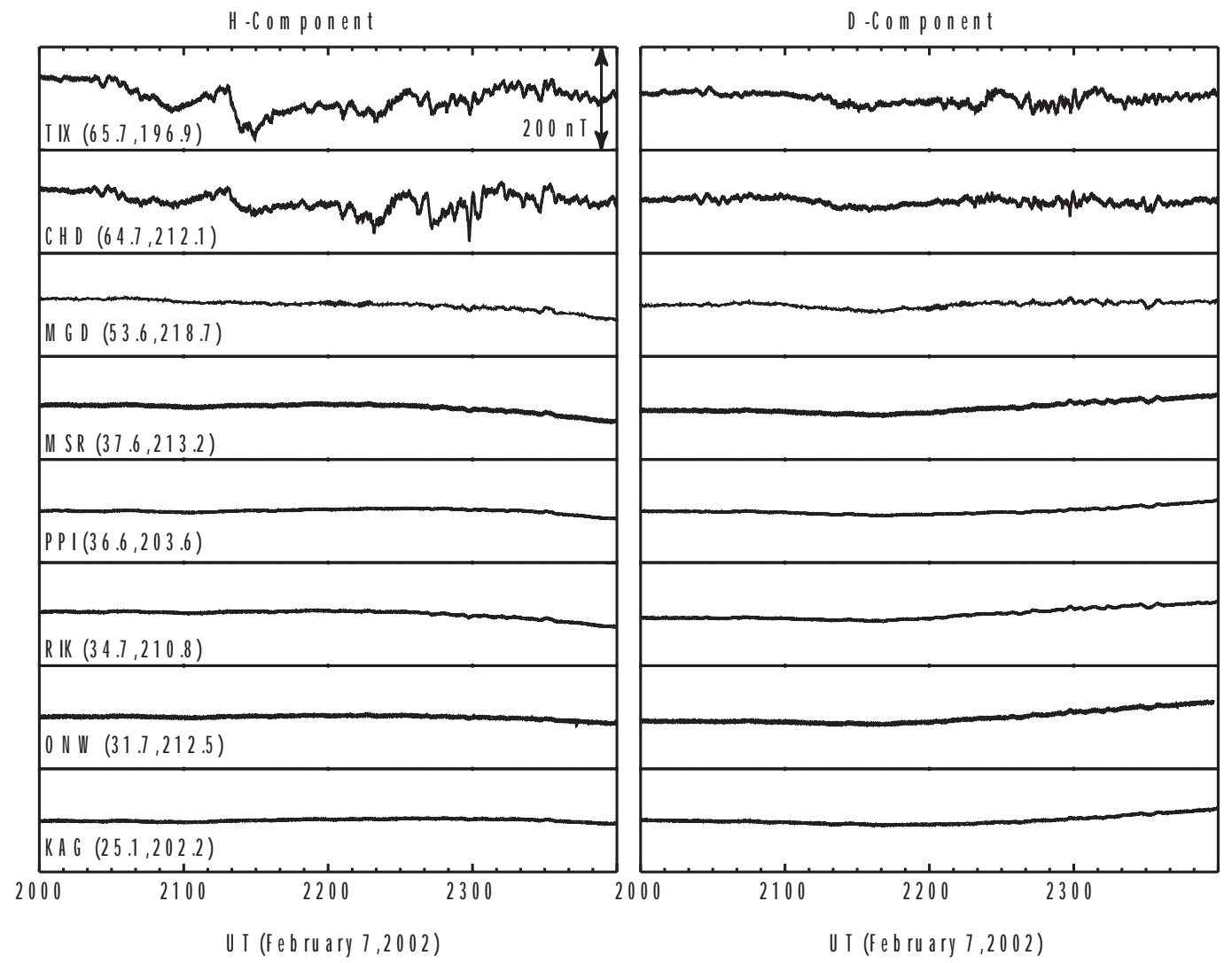

Fig. 12. The stacked horizontal components $(H$ and $D)$ of the magnetic field from the 210-MM array stations in the Asia/Pacific sector for a 4-h period from 20:00 to 24:00 UT. In each right panel, the numbers next to the station name give the CGM latitude and longitude of the station.

is much larger than the model predictions based on patchy reconnection on the magnetopause.

For the strong FTE observed at 22:40-22:43 UT by the Polar spacecraft, we have used its ground signatures in the $H$-component to estimate the propagating time delay from the spacecraft to CANOPUS ground stations. At Polar, the core of the FTE occurred at 22:41:20 UT, when the Polar spacecraft mapped to $73.3^{\circ} \mathrm{CGM}$ latitude and $310.6^{\circ} \mathrm{CGM}$ longitude at its footprint. The arrival time at the ground stations is taken as the time of the most northward or southward perturbation in the $H$-component. A timing uncertainty of $5 \mathrm{~s}$ is possible since for the time resolution of the CANOPUS data we used $5 \mathrm{~s}$.

We find that the arrival time at the ground station is ordered by the station's longitude. Figure 15 shows the time delays from Polar to CANOPUS stations as a function of the longitudinal distance from the Polar footprint. The time delay increases as the station's longitude increases. Thus, the signal moves eastward, or duskward in local time. The solid line is the linear regression of the data, from which we estimate that the time delay from the Polar spacecraft to its footprint is $\sim 80 \mathrm{~s}$, and the eastward motion of the FTE ground signature is $\sim 0.75^{\circ} / \mathrm{s}$. Using the dipolar field line length from the Polar spacecraft to its footprint, we estimate that the
Alfvén velocity at which the FTE signature propagates from Polar to its footprint was $\sim 560 \mathrm{~km} / \mathrm{s}$. Previous studies have given a much higher estimate of the Alfvén velocity in the range of $\sim 1000$ to $2000 \mathrm{~km} / \mathrm{s}$ near the magnetopause based on the measurement of the magnetic field and thermal plasma (e.g. Burton et al., 1970). However, in this study, the Alfvén velocity has been significantly reduced, consistent with the presence of cold, dense ion bursts of ionospheric origin near the magnetopause.

\subsection{Longitudinal extent of FTE X-line}

The longitudinal time delay of the FTE ground signature shows a $\sim 0.75^{\circ} / \mathrm{s}$ eastward motion, which corresponds to a speed of $\sim 31 \mathrm{~km} / \mathrm{s}$ in the ionosphere. Such a speed is much bigger than the $\sim 0.5-3 \mathrm{~km} / \mathrm{s}$ traveling speed one would expect in the ionosphere due to the anti-sunward convection of a FTE flux tube based on the patchy reconnection model of FTEs (McHenry and Clauer, 1987; Chaston et al., 1993). The large speed implies that the reconnection may occur simultaneously over an extended $X$-line on the magnetopause and map to an extended longitudinal range in the ionosphere. In this case, at least two factors contribute to the observed large eastward (or duskward) motion of FTE ground signatures in the post-noon dayside sector. First, the ground signature of 


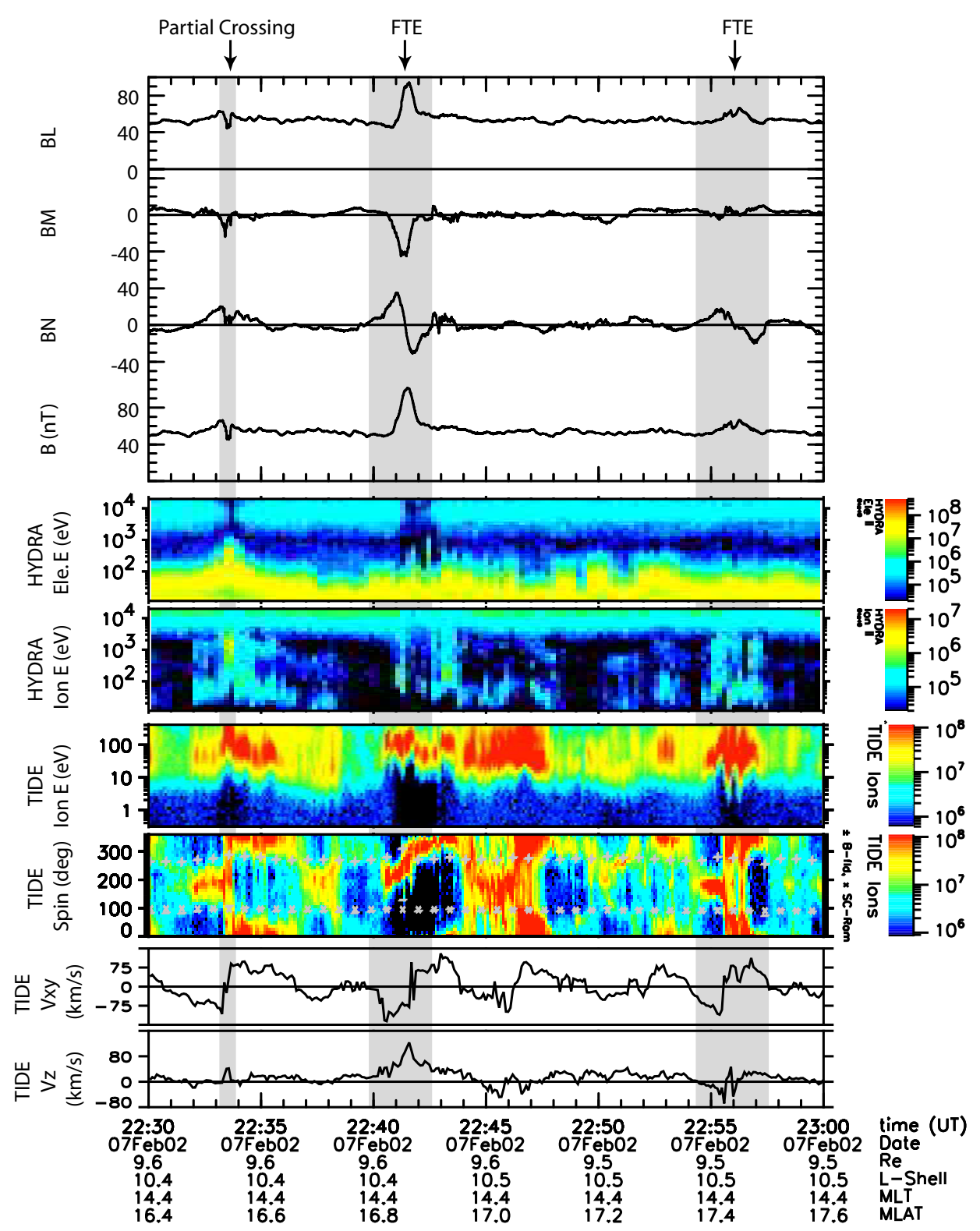

Fig. 13. High-resolution magnetic field data and plasma data from 22:30 to 23:00 UT showing two flux transfer events. The format is the same as Figs. 5a and b, except that the magnetic field data here are displayed in the local boundary normal coordinates.

a duskward propagating perturbation at the equatorial magnetopause will show similar duskward motion. Second, the length of the magnetic field line from the equatorial magnetopause to its footprint increases from noon to dusk. It takes longer time for a wave at a later local time to propagate along the field line from the equatorial region to the ionospheric footprint, assuming the Alfvén velocity is the same. This effect alone may result in an eastward time delay on the ground for a signature that simultaneously occurs over a large longitudinal range at the equatorial magnetopause.

Assessing the relative contribution of the above two factors has important implications for the nature of FTEs, in particular the longitudinal extent of the reconnection $X$-line. Using the model magnetopause position scaled by the Polar observations (shown in Fig. 3), the length of the magnetic field line from the equatorial magnetopause to its ionospheric footprint is estimated to be $\sim 11.7 \mathrm{R}_{E}$ at the Polar local time based on a simple dipolar field model. The field line length is $\sim 0.6 \mathrm{R}_{E}$ shorter at FSIM local time, and $\sim 1.3 \mathrm{R}_{E}$ longer at Churchill line local time. Using the Alfvén velocity of $\sim 560 \mathrm{~km} / \mathrm{s}$ estimated earlier, the varying length of the magnetic field line will introduce a time delay of $\sim 7 \mathrm{~s}$ from FSIM to the Polar footprint, and $\sim 15 \mathrm{~s}$ from the Polar footprint to the Churchill line, or a total of $\sim 22 \mathrm{~s}$ from FSIM to the Churchill line. Since the total observed time delay from FSIM to the Churchill line was $\sim 53 \mathrm{~s}$ (Fig. 15), only an $\sim 31$-s time delay was due to the eastward (duskward) convection of the FTE at the magnetopause. 


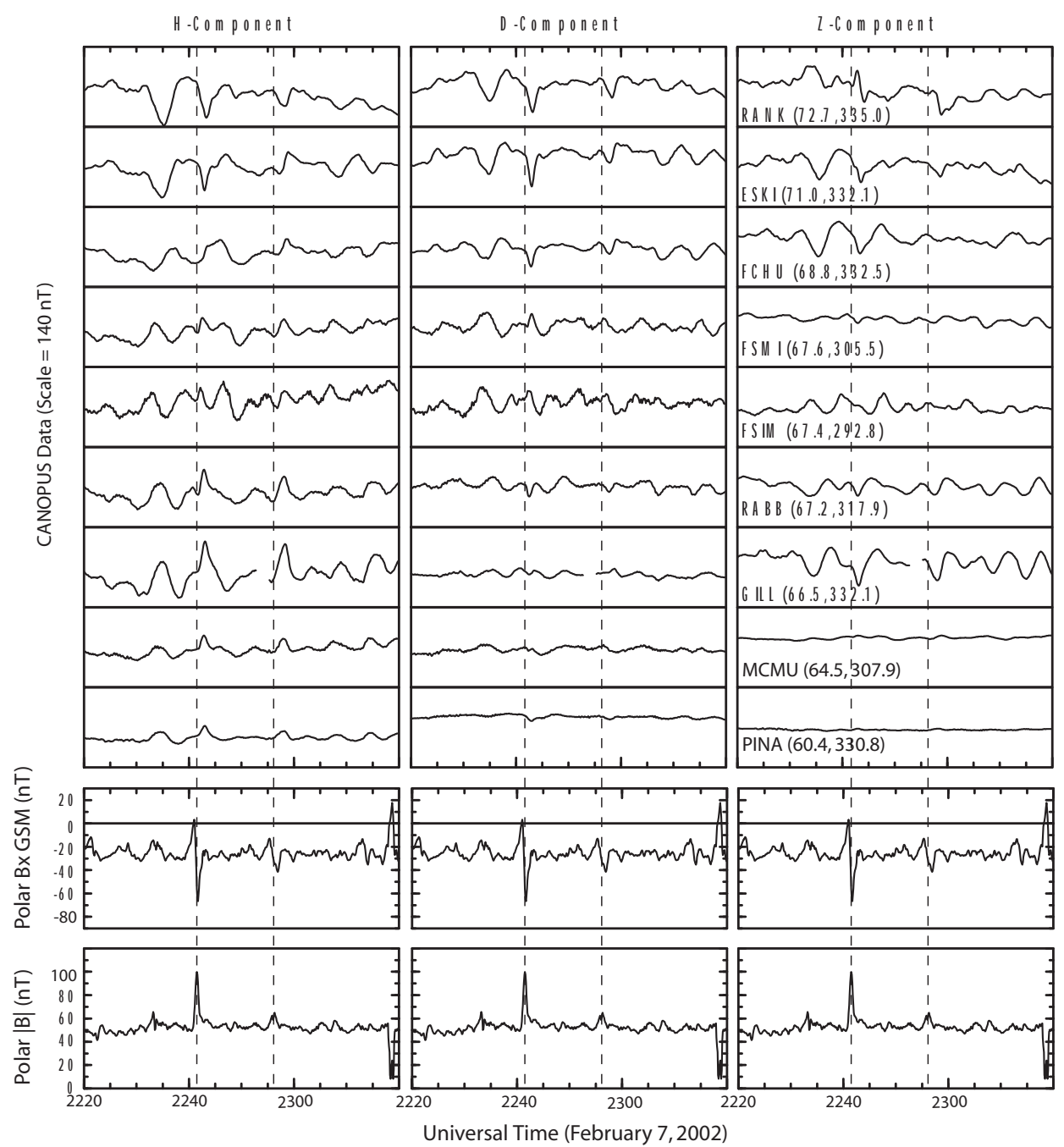

Fig. 14. Expanded view of the CANOPUS magnetic field data, as well as the simultaneous Polar $B_{x}$-component in GSM coordinates and the field strength showing the ground signature of flux transfer events.

Figure 16 illustrates how we estimate the longitudinal extent of the reconnection $X$-line where the flux transfer event occurred, using a simplified dipolar magnetic field model. At the time of the flux transfer event at 22:41:20 UT, magnetic field lines from the equatorial magnetopause to the ionospheric footprints are drawn at three local times corresponding to FSIM, the Polar footprint, and the Churchill line. The longitudinal distance at the equatorial magnetopause from FSIM to the Churchill line is estimated to be $\sim 6.6 \mathrm{R}_{E}$. The flow velocity in the magnetosheath at these local times ranges from $\sim 0.2$ to 0.5 times the solar wind speed (Spreiter et al., 1966; Spreiter and Stahara, 1980), and we use 0.5 times the solar wind speed, or $\sim 280 \mathrm{~km} / \mathrm{s}$ as an upper limit. Now, assume that the reconnection occurred simultaneously along the $X$-line with a longitudinal extent of $X$. Since the time delay at the magnetopause from the FSIM local time to the Churchill line local time is $\sim 31 \mathrm{~s}$, we have $\left(6.6 R_{E}-X\right) / 280 \mathrm{~km} / \mathrm{s}=31 \mathrm{~s}$, which results in a lower limit of $\sim 5.2 \mathrm{R}_{E}$ longitudinal extent for the FTE $X$-line. The

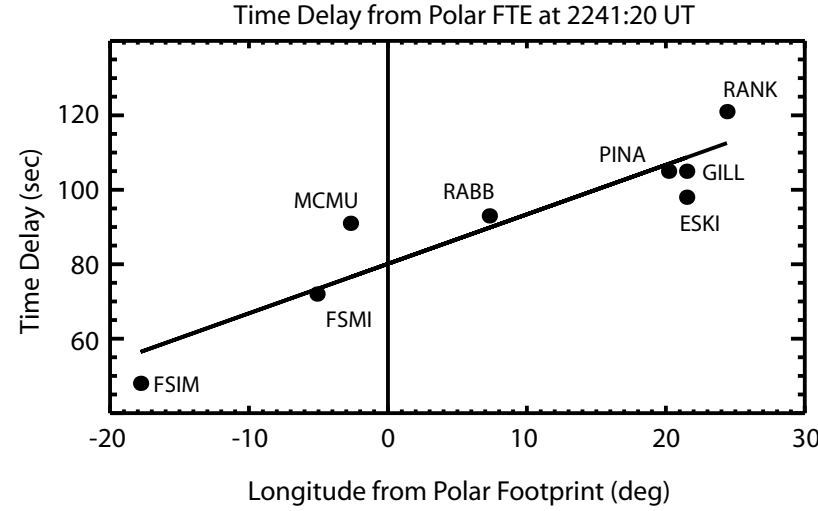

Fig. 15. Time delays of the FTE signature from Polar to the CANOPUS stations as a function of the longitudinal distance from the Polar footprint. 


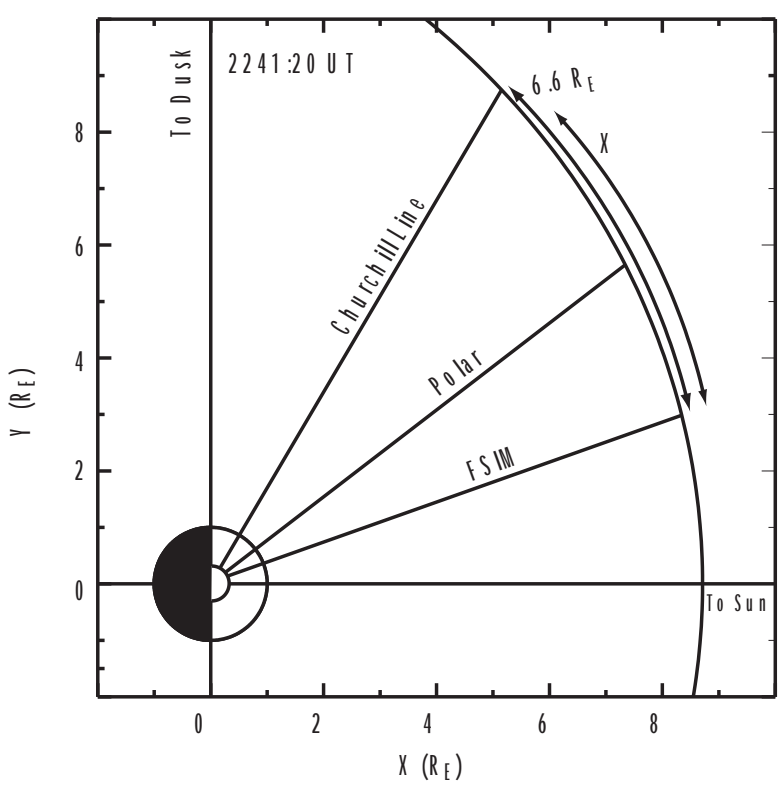

Fig. 16. Schematic showing the longitudinal extent of the reconnection $X$-line where the flux transfer event occurred. At the time of the flux transfer event at 22:41:20 UT, magnetic field lines from the equatorial magnetopause to the ionospheric footprints are drawn at three local times corresponding to FSIM, Polar footprint, and the Churchill line, using a simple dipolar magnetic field line. The longitudinal distance at the equatorial magnetopause from FSIM to the Churchill line is estimated to be $\sim 6.6 \mathrm{R}_{E}$.

estimated longitudinal extent is much larger than the scale size of the flux tube in the boundary normal direction, $\sim 1 \mathrm{R}_{E}$ (Saunders et al., 1984).

\section{Discussion}

Coordinated spacecraft and ground-based observations reveal that magnetospheric Pc5 pulsations at geosynchronous orbit and on the ground on 7 February 2002, were directly driven by surface waves on the magnetopause boundary at the same frequency. They are the results of forced oscillations of the magnetospheric flux tubes in the shell adjacent to the magnetopause. Although the Polar observations of the magnetopause and vicinity were made at one local time when it was skimming the magnetopause meridian plane at $\sim 14: 30 \mathrm{LT}$, the simultaneous observations at geosynchronous orbit and on the ground show that the pulsations were not a global phenomenon. Instead, they occurred in a limited local time range of $\sim 4 \mathrm{~h}$ in the post-noon dayside sector ( 14:00-18:00 LT). They did not appear to continue into the nightside sector, near noon, or in the morning sector. The pulsations also occurred only in a limited latitude range, within $\sim 6^{\circ}$ of the open-closed field line boundary on the ground, which maps to a shell extending from the magnetopause (with $\sim 8.6 \mathrm{R}_{E}$ standoff distance) to $\sim 1 \mathrm{R}_{E}$ inward from the geosynchronous orbit. These observations suggest that the magnetopause oscillations did not occur everywhere on the magnetopause, and the source mechanism responsible for the observed magnetopause oscillations and surface wave only acted in a limited local time range on the boundary.

Among the possible mechanisms, Kelvin-Helmholz instability, excited when the magnetosheath flow velocity exceeds a certain threshold, is the most cited one for the generation of surface waves at the magnetopause, especially for waves observed near the flanks (e.g. Chen and Kivelson, 1993; Sarafopoulos et al., 2001; Mann et al., 2002). However, in our study, we do not consider the Kelvin-Helmholz instability to be the cause of the observed surface waves and magnetopause oscillations since their occurrence characteristics did not suggest so. Although the event occurred during a high-speed solar wind stream which favors the K-H instability, the Pc5 waves did not appear to be a global phenomenon as shown in other studies (Sarafoupoulos et al., 2001; Mann et al., 2002). They were absent in the dusk flank (past $\sim 18: 00 \mathrm{LT}$ ) and in the morning flank, the region where the $\mathrm{K}-\mathrm{H}$ instability is most effective. Instead, the Pc5 waves excited in the magnetosphere appeared to be a longitudinally localized dayside phenomenon. They were only seen in a limited dayside region within $\sim$ 14:00-18:00 local time.

The other possible mechanism for the surface wave and boundary oscillation is fluctuations of the solar wind dynamic pressure in the same frequency range. During highspeed solar streams, large-amplitude fluctuations in the broad-band Pc5 range are very common in the solar wind (Burlaga and Ogilvie, 1970; Belcher and Davis, 1971). The Pc5 power in high-speed solar wind streams is found to correlate well with the total Pc5 power of the ground-based magnetic field (Kessel et al., 2004). The role of the solar wind dynamic fluctuations is twofold: it could directly drive the magnetopause boundary motion (Wright and Richard, 1995; Kepko et al., 2002) or it could serve as seed perturbations of boundary motion to be enhanced by the K-H instability on the flanks (Engbretson et al., 1998). However, given the large-scale size of the high-speed solar wind streams in comparison with the size of the magnetosphere, the magnetospheric response to the solar wind dynamic pressure fluctuations in the Pc5 band is expected to be global over the entire dayside magnetopause. It is unlikely that the observed magnetopause oscillation on 7 February 2002, which was limited to the $\sim 14: 00-18: 00$ LT range, was the boundary displacement directly driven by the dynamic pressure fluctuations in the high-speed solar wind stream.

Another source of fluctuations of the solar wind dynamic pressure is the localized pressure enhancement generated in the foreshock upstream from the quasi-parallel shock region (e.g. Sibeck et al., 1989; Sibeck, 1990). During the 3-h interval of the event, the IMF cone angle was small since the IMF $\mathrm{B}_{x}$ was the dominant component with a steady, negative value at both ACE and Wind, and the IMF $\mathrm{B}_{y}$ component fluctuated around zero with a slightly positive average value (Fig. 2). For a negative IMF $\mathrm{B}_{x}$, the foreshock region is expected to be in the dawn side for a positive IMF $\mathrm{B}_{y}$ and the dusk side for a negative IMF $\mathrm{B}_{y}$. Thus, for most of the time during the 3-h interval, the foreshock spanned from the 
subsolar region to the dawn flank. This is consistent with the presence of Pc3-4 waves in the morning sector, as seen by the $210 \mathrm{MM}$ magnetometer array, and the absence of Pc34 waves in the afternoon sector, as seen by the CANOPUS magnetometer array. Since the oscillating magnetopause occurred only in the post-noon dayside sector and lasted for $\sim 3 \mathrm{~h}$, we do not expect that the foreshock generated pressure pulses would be the cause of it.

In the event in this study, the source mechanism for the observed magnetopause oscillation appeared to take place only in a limited local time region of the dayside magnetopause. We have already presented evidence that reconnection was at work during the event as two flux transfer events were observed at the magnetopause and on the ground within the same local time range. It is natural to consider the boundary motion in response to pulsed reconnection at the magnetopause as the mechanism involved. Due to the lack of a near-Earth solar wind monitor, we do not have definitive knowledge of the IMF $\mathrm{B}_{z}$ component at the nose of the magnetopause during the interval of interest. But both the Wind and ACE spacecraft observations indicated that the IMF was southward, on average (Fig. 2). During the two brief excursions of the Polar spacecraft into the magnetosheath, the magnetosheath magnetic field was southward (Figs. 5a and b). Furthermore, the magnetopause standoff distance was found to be smaller than one would expect based on the observed solar wind dynamic pressure. Thus, it is reasonable to believe that the IMF was mainly southward at the nose of the dayside magnetopause, which imposed a favorable condition for reconnection at the dayside magnetopause.

Dense ionospheric ion bursts present in the shell immediately earthward to the magnetopause have been reported previously in observations by Cluster (Sauvaud et al., 2001) and Polar (Chen and Moore, 2004). Their density reached $\sim 1-100 \mathrm{~cm}^{-3}$ and the velocity reached $\sim 100 \mathrm{~km} / \mathrm{s}$ in the direction perpendicular to the local magnetic field. These ionospheric ions on closed field lines were directly linked to the magnetopause boundary motion, which results in fluctuations in local electric field and accelerates these ions. Sauvaud et al. (2001) speculated that the boundary motions were caused by solar wind pressure changes. But Chen and Moore (2004) pointed out that the speed of these ions was on the order of $\sim 0.3$ local Alfvén Mach number perpendicular to the magnetic field, and implied a reconnection rate of the same magnitude, which is above the estimates in rapid reconnection models. Thus, the presence of these ions was interpreted as the result of low-latitude reconnection drawing internal magnetospheric plasma of ionospheric sources to the boundary layer as the reconnection peels away dayside flux tubes. Our observations are consistent with this reconnection interpretation.

The observations from this study suggest that reconnection occurred in two different forms at the dayside magnetopause: 1) continuous reconnection with a pulsed reconnection rate, and 2) transient reconnection as flux transfer events. Both forms of reconnection took place simultaneously in the same general region of the magnetopause. Their ionospheric signatures are different. In this case, continuous reconnection took place for $\sim 2.3 \mathrm{~h}$ in duration with a periodically pulsed reconnection rate, which induced the magnetopause oscillation along the reconnection $X$-line. The longitudinal extent of the $X$-line spanned $\sim 52^{\circ}$, based on the simultaneous observations of the resulting Pc5 pulsations in the magnetosphere (longitudinal distance from FSMI to GOES 8). The flux transfer events appeared to be a transient burst of enhanced reconnection rate. Their ionospheric signature appeared to be an isolated unipolar perturbation in the $H$ component. The polarity of the perturbation was southward near the open-closed field line boundary, corresponding to a westward Hall current in the ionosphere above the station, and changed to northward at lower latitudes, corresponding to an eastward Hall current. We have estimated that the longitudinal extent of the reconnection $X$-line spanned $\sim 43^{\circ}$, and was $\sim 5.2 \mathrm{R}_{E}$ long based on the time delay of the ground signatures of the FTEs (Fig. 14). Thus, the longitudinal scale size of FTEs is much larger than that along the boundary normal direction. This result suggests that flux transfer events are produced by transient reconnection along a single extended $X$-line, and magnetic field lines connected to the ionosphere from the magnetopause over a large longitudinal region. This observation provides evidence for the bursty reconnection model proposed by Scholer (1988) and Southwood et al. (1988).

Pulsed but continuous reconnection has been reported previously in many observational studies (e.g. Sandholt et al., 1992; Lockwood and Davis, 1995; Sedgemore-Schulthess et al., 1999; Phan et al., 2001; Kuznetsova et al., 2002; Frey et al., 2003). The pulses in the reconnection rate were commonly attributed to the quasi-periodic changes in the IMF $\mathrm{B}_{z}$ direction. But periodic pressure pulses may also modulate the reconnection rate in the same fashion (Lanzerotti, 1989). It has been suggested that pressure pulses could trigger reconnection as they thin and destabilize the magnetopause current layer (Kan, 1989; Elphic, 1990). In our case, we think that the Pc5 band dynamic pressure fluctuations occurring in the high-speed solar wind stream (Kessel et al., 2004) may be an indirect source of the observed Pc5 pulsations.

\section{Conclusions}

On 7 February 2002 during a high-speed solar stream, the Polar spacecraft was skimming the magnetopause in the 14:30 LT meridian plane for $\sim 3 \mathrm{~h}$. During this interval, it made two short excursions and a few partial crossings into the magnetosheath and observed quasi-periodic, cold ion bursts in the region adjacent to the magnetopause current layer. The multiple magnetopause crossings, as well as the flow velocity of the ion bursts indicate that the magnetopause was oscillating with an $\sim 6 \mathrm{~min}$ period during this interval. The analysis of the magnetopause current layer showed that the magnetopause oscillations are consistent with the surface waves on the magnetopause. Simultaneous observations of 
Pc5 waves at geosynchronous orbit by the GOES spacecraft and on the ground by the CANOPUS magnetometer array reveal that the magnetospheric pulsations were directly caused by forced oscillations of magnetic field lines in response to the magnetopause oscillations. They occurred only in the region spanning $\sim 52^{\circ}$ in longitudes and $\sim 6^{\circ}$ in latitudes southward of the open-closed field lines, and thus were not a global phenomenon as one would expect for global field line resonance. Thus, the magnetopause oscillations were also limited to a localized region spanning $\sim 4 \mathrm{~h}$ in local time in the postnoon dayside sector. These observations suggest that it is unlikely that the K-H instability and/or fluctuations in the solar wind dynamic pressure were the direct driving mechanisms for the observed boundary oscillations since the magnetospheric response to these processes is expected to be global. Instead, the likely mechanism for the localized boundary oscillations acted only in the same localized region in the postnoon dayside sector. A good candidate for the responsible mechanism is pulsed reconnection at the magnetopause occurring along the $X$-line, extending over the $\sim 4$-h region.

During the oscillating magnetopause interval, we also observed two flux transfer events in the magnetosphere near the magnetopause and identified their ground signatures in the CANOPUS data. The time delays of the FTE signatures from the Polar spacecraft to the ground stations enable us to estimate that the longitudinal extent of the reconnection $X$-line at the magnetopause was $\sim 43^{\circ}$ or $\sim 5.2 \mathrm{R}_{E}$. The coordinated in-situ and ground-based observations suggest that FTEs are produced by transient reconnection taking place along a single extended $X$-line at the magnetopause, as suggested in the models by Scholer (1988) and Southwood et al. (1988). The observations from this study suggest that the reconnection occurred in two different forms simultaneously in the same general region at the dayside magnetopause: 1) continuous reconnection with pulsed reconnection rate, and 2) transient reconnection as flux transfer events.

Acknowledgements. The solar wind plasma and magnetic field data were obtained from the CDAWeb. We wish to thank K. Ogilvie for providing WIND solar wind data, R. Lepping for Wind magnetic field data, N. Ness for ACE magnetic field data, and D. J. McComas for ACE solar wind data. The CANOPUS instrument array constructed, maintained and operated by the Canadian Space Agency, provided the data used in this study. The $210 \mathrm{MM}$ data were obtained ceaselessly by the CPMN group (PI, K. Yumoto, Space Environment Research Center, Kyushu University), and provided by the Solar-Terrestrial Environment Laboratory, Nagoya University. Work by S.-H. Chen was supported the Polar Mission under UPN 370-08-43 and by the NASA Office of Space Science Sun Earth Connection theme Research and Analysis program under UPN 43201-42. Work by C. T. Russell was supported by the National Aeronautics and Space Administration (NASA) under research grant NAG5-11324. Work by C.-S. Huang at MIT Haystack Observatory was supported by a NSF cooperative agreement with Massachusetts Institute of Technology. Work by S. Petrinec was supported by the National Aeronautics and Space Administration (NASA) under research grant NAS5-30372.

Topical Editor T. Pulkkinen thanks M. Scholer and A. Masson for their help in evaluating this paper.

\section{References}

Anderson, B. J., Potemra, T. A., Zanetti, L. J., and Engebretson, M. J.: Statistical correlations between Pc3-5 pulsations and solar wind/IMF parameters and geomagnetic indices, in: Physics of Space Plasmas (1990), SPI Conf. Proc. Reprint Ser., 10, edited by: T. Chang et al., 419-429, Scientific, Cambridge, Mass., 1991.

Aubry, M. P., Kivelson, M. K., and Russell, C. T.: Motion and structure of the magnetopause, J. Geophys. Res., 76, 1673-1696, 1971.

Baker, G. J., Donovan, E. F., and Jackel, B. J.: A comprehensive survey of auroral Pc5 pulsation characteristics, J. Geophys. Res. 108(A10), 1384, doi:10.1029/2002JA009801, 2003.

Belcher, J. W. and Davis, L.: Large-amplitude Alfvén waves in interplanetary medium, 2, J. Geophys. Res., 76, 3534-3563, 1971.

Burlaga, L. F. and Ogilvie, K. W.: Magnetic and thermal pressures in the solar wind, Solar Phys., 15, 61-71, 1970.

Burton, R. K., Russell, C. T., and Chappell, C. R.: The Alfvén velocity in the magnetosphere and its relationship to ELF emissions, J. Geophys. Res., 75, 5582-5586, 1970.

Cahill, L. J. and Patel., T. V. L.: The boundary of the geomagnetic field, August to November, 1961, Planet. Space Sci., 15, 9971033, 1967.

Cahill, L. J. Jr. and Skillman, T. L.: The magnetopause at $5.2 \mathrm{R}_{E}$ in August 1972: Magnetopause motion, J. Geophys. Res., 82, 1566-1572, 1977.

Chaston, C. C., Hanson, H. J., and Menk, F. W. et al.: Ground signatures of convecting reconnected flux tubes, J. Geophys. Res. 98, 19 151-19 162, 1993.

Chen, L. and Hasagawa, A.: A theory of long-period magnetic pulsations, 1 . Steady state excitation of field line resonance, J. Geophys. Res., 79, 1024-1037, 1974a.

Chen, L. and Hasagawa, A.: A theory of long-period magnetic pulsations, 2. Impulsive excitation of surface eigen-mode, J. Geophys. Res., 79, 1033-1037, 1974b.

Chen, S. H. and Kivelson, M. G.: On nonsinusoidal waves at the Earth's magnetopause, Geophys. Res. Lett., 20, 2699-2702, 1993.

Chen, S. H., Kivelson, M. G., Gosling, J. T., Walker, R. J., and Lazarus, A. J.: Anomalous aspects of magnetosheath flow and of the shape and oscillations of the magnetopause during an interval of strongly northward interplanetary magnetic-field, J. Geophys. Res., 98, 5727-5742, 1993.

Chen, S.-H. and Kivelson, M. G.: On ultralow frequency waves in the lobes of the Earth's magnetotail, J. Geophys. Res., 96, 15 711-15 723, 1991.

Chen, S.-H. and Moore, T. E.: Dayside flow bursts in the Earth's outer magnetosphere, J. Geophys. Res., 109, A03215, doi:10.1029/2003JA010007, 2004.

Cowley, S. W. H.: The causes of convection in the Earth's magnetosphere, A review of developments during the IMF, Rev. Geophys., 20, 531-565, 1982.

Elphic, R. C.: Observations of flux transfer events: Are FTEs flux ropes, islands, or surface waves?, in: Physics of Magnetic Flux Ropes, Geophys. Monogr. Ser., 58, edited by: C. T. Russell, E. R. Priest, and L. C. Lee, 455-471, AGU, Washington, D.C., 1990.

Elphic, R. C., Lockwood, M., Cowley, S. W. H., and Sandholt, P. E.: Flux transfer events at the magnetopause and in the ionosphere, Geophys. Res. Lett., 17, 2441-2445, 1990.

Engebretson, M. J., Glassmeier, K.-H., and Stellmacher, M.: The dependence of high-latitude Pc5 power on solar wind velocity 
and phase of high-speed solar wind streams, J. Geophys. Res., 103, 26 271-26283, 1998.

Frey, H, U., Phan, T. D., Fuselier, S. A., and Mende, S. B.: Continuous magnetic reconnection at Earth's magnetopause, Nature, 424, 533-537, 2003.

Glassmeier, K.-H., and Stellmacher, M.: Mapping flux transfer events to the ionosphere, Adv. Space Res., 18, 151-160, 1996.

Glassmeier, K. H., Lester, M., Mierjedrzejowicz, W. A. C., Green, C. A., Rostoker, G., Orr, D., Wedeken, U., Junginger, H., and Amata, E.: Pc5 pulsations and their possible source mechanisms - A case-study, J. Geophys. Res., 55, 108-119, 1984.

Goertz, C. K., Nielsen, E., Korth, A., Glassmeier, K. H., Haldoupis, C., Hoeg, P., and Hayward, D.: Observations of a possible ground signature of flux transfer events, J. Geophys. Res., 90, 4069-4078, 1985.

Holzer, R. E., McLeod, M. G., and Smith, E. J.: Preliminary results from Ogo 1 search coil magnetometer: Boundary positions and magnetic noise spectra, J. Geophys. Res., 71, 1481-1486, 1966.

Kan, J. R.: A theory of patchy and intermittent reconnections for magnetospheric flux transfer events, J. Geophys. Res., 93, 5613$5623,1989$.

Kaufmann, R. L. and Cahill Jr., L. J.: The magnetopause at 5.2 RE on 4 August 1972: Magnetopause shape and structure, J. Geophys. Res., 82, 1573-1584, 1977.

Kepko, L., Spence, H. E., and Singer, H. J.: ULF waves in the solar wind as direct drivers of magnetosheric pulsations, Geophys. Res. Lett., 29, 1197, 10.1029/2002GL014405, 2002.

Kessel, R. L., Mann, I. R., Fung, S. F., Milling, D. K., and O'Connell, N.: Correlation of Pc5 wave power inside and outside the magnetosphere during high speed streams, Ann. Geophys., 22, 629-641, 2004.

Kuo, H., Russell, C. T., and Le, G.: Statistical studies of flux transfer events, J. Geophys. Res., 100, 3513-3519, 1995.

Kuznetsova, T. V., Tsirulnik, L. B., and Oditsov, V. I.: Interpretation of observations on July 24, 1996 detected by Interball-1 as pulsed reconnection at low latitude magnetopause, Adv. Space Res., 30, 2757-2762, 2002.

Lanzerotti, L. J.: Comment on Solar wind dynamic pressure variations and transient magnetospheric signatures, Geophys. Res. Lett., 16, 1197-1199, 1989.

Lanzerotti, L. J., Lee, L. C., Maclennan, C. G., Wolfe, A., and Medford, A.: Possible evidence of flux-transfer events in the polar ionosphere, Geophys. Res. Lett., 13, 1089-1092, 1986.

Lockwood, M. and Smith, M. F.: The variation of reconnection rate at the dayside, Magnetopause and cusp ion precipitation, J. Geophys. Res., 97, 14 841-14 847, 1992.

Lockwood, M. and Davis, C. J.: Occurrence probability, width and number of steps of cusp precipitation for fully pulsed reconnection at the dayside magnetopause, J. Geophys. Res., 100, $7627-$ 7640, 1995.

Lui, A. T. Y.: Current controversies in magnetospheric physics, Rev. Geophys., 39, 535-563, 2001.

Mann, I. R., Voronkov, I., Dunlop, M., Donovan, E., Yeoman, T. K., Milling, D. K., Wild, J., Kauristie, K., Amm, O., Bale, S. D., Balogh, A., Viljanen, A., and Opgenoorth, H. J.: Coordinated ground-based and Cluster observations of large amplitude global magnetospheric oscillations during a fast solar wind speed interval, Ann. Geophys., 20, 405-425, 2002.

McHenry, M. A. and Clauer, C. R.: Modeled Ground Magnetic Signatures of Flux-Transfer Events, J. Geophys. Res., 92, 11 231$11240,1987$.

Miura, A.: Kelvin-Helmholz instability at the magnetospheric boundary: Dependence on the magnetosheath sonic Mach number, J. Geophys. Res., 97, 10 665-10 675, 1992.

Moore, T. E., Chappell, C. R., Chandler, M. O., Fields, S. A., Pollock, C. J., Reasoner, D. L., Young, D. T., Burch, J. L., Eaker, N., Waite, J. H. Jr., McCommas, D. J., Nordholdt, J. E., Thomsen, M. F., Berthelier, J. J., and Robson, R.: The Thermal Ion Dynamics Experiment and Plasma Source Instrument, Space Sci. Rev., 71, 409-458, 1995.

Neudegg, D. A., Yeoman, T. K., Cowley, S. W. H., Provan, G., Haerendel, G., Baumjohann, W., Auster, U., Fornacon, K.-H., Georgescu, E., and Owen, C. J.: A flux transfer envent observed at the magnetopause by the Equator-S spacecraft and in the ionosphere by the CUTLASS HF radar, Ann. Geophys., 17, 707-711, 1999.

Neudegg, D. A., Cowley, S. W. H., and McWilliams, K. A., et al.: The UV aurora and ionospheric flows during flux transfer events, Ann. Geophys., 19, 179-188, 2001.

Petrinec, S. M. and Russell, C. T.: External and internal influences on the size of the dayside terrestrial magnetosphere, Geophys. Res. Lett., 20, 339-342, 1993.

Phan, T. D., Sonnerup, B. U. O., and Lin, R. P.: Fluid and kinetic signatures of reconnection at the dawn tail magnetopause: Wind observations, J. Geophys. Res., 106, 25 489-25 501, 2001.

Pitout, F., Eglitis, P., and Blelly, P.-L.: High-latitude dayside ionosphere response to Pc5 field line resonance, Ann. Geophys., 21, 1509-1520, 2003.

Prikryl, P., Greenwald, R. A., Sofko, G. J., Villain, J. P., Ziesolleck, C. W. S., and Friis-Christensen, E.: Solar-wind-driven pulsed magnetic reconnection at the dayside magnetopause, Pc5 compressional oscillations, and field line resonances, J. Geophys. Res., 103, 17 307-17 322, 1998.

$\mathrm{Pu}, \mathrm{Z}$.-Y. and Kivelson, M. G.: Kelvin-Helmholz instability at the magnetopause: Solution for compression plasmas, J. Geophys. Res., 88, 841-852, J. Geophys. Res., 88, 841-852, 1989.

Rostoker, G., Samson, J. C., Creutzberg, F., Hughes, T. J., McDiarmid, D. R., McnNamara, A. G., Jones, A. V., Wallis, D. D., and Cogger, L. L.: CANOPUS - A ground-based instrument array for remote-sensing the high-latitude ionosphere during the ISTP/GGS program, Space Sci. Rev., 71, 743-760, 1995.

Russell, C. T. and Elphic, R. C.: Initial ISEE magnetometer results: Magnetopause observations, Space Sci. Rev., 22, 681-715, 1978.

Russell, C. T., Snare, R. C., Means, J. D., Pierce, D., Dearborn, D., Larson, M., Barr, G., and Le, G.: The GGS POLAR magnetic fields investigation, Space Sci. Rev., 71, 563-582, 1995.

Russell, C. T., Petrinec, S. M., Zhang, T. L., Song P., and Kawano, H.: The effect of foreshock on the motion of the dayside magnetopause, Geophys. Res. Lett., 24, 1439-1442, 1997.

Sandholt, P. E., Moen, J., and Opsvik, D.: Periodic auroral events at the midday polar cap boundary: Implications for solar windmagnetosphere coupling, Geophys. Res. Lett., 19, 1223-1226, 1992.

Sarafopoulos, D. V., Takahashi, K., and McEntire, R. W.: Periodic variations of magnetosheath energetic electron flux associated with global Pc5 pulsations, J. Geophys. Res., 106, $13037-$ $13051,2001$.

Saunders, M. A., Russell, C. T., and Sckopke, N.: Flux transfer events: scale size and interior structure, Geophys. Res. Lett., 11, 131-134, 1984.

Sauvaud, J.-A., Lundin, R., Rème, H., and McFadden, J. P., et al.: Intermittent thermal plasma acceleration linked to sporadic motions of the magnetopause, first Cluster results, Ann. Geophys. 19, 1523-1532, 2001. 
Scholer, M.: Magnetic flux transfer at the magnetopause based on single X line bursty reconnection, Geophys. Res. Lett., 15, 291294, 1988.

Scudder, J., Hunsacker, F., Miller, G., Lobell, J., et al.: HYDRA - a 3-D electron and ion hot plasma instrument for the POLAR spacecraft of the GGS mission, Space Sci. Rev., 71, 459-495, 1995.

Sedgemore-Schulthess, K. J. F., Lockwood, M., Trondsen, T. S., Lanchester, B. S., Rees, M. H., Lorentzen, D. A., and Moen, J.: Coherent EISCAT Svalbard Radar spectra from the dayside cusp/cleft and their implications for transient field-aligned currents, J. Geopyhs. Res., 104, 24 613-24 624, 1999.

Sibeck, D. G.: A model for the transient magnetospheric response to sudden solar wind dynamic pressure variations, J. Geophys. Res., 95, 3755-3771, 1990.

Sibeck, D. G., Baumjohann, W., Elphic, R. C., Fairfield, D. H., Fennell, J. F., Gail, W. B., Lanzerotti, L. J., Lopez, R. E., Luehr, H., Lui, A. T. Y., Maclennan, C. G., Mcentire, R. W., Potemra, T. A., Rosenberg, T. J., and Takahashi, K.: The magnetospheric response to 8-min-period strong amplitude upstream pressure variations, J. Geophys. Res., 94, 2505-2519, 1989.

Singer, H. J., Russell, C. T., Kevelson, M. G., Greenstadt, E. W., and Olson, J. V.: Evidence for the control of Pc3-4 magnetic pulsations by the solar wind velocity, Geophys. Res. Lett., 4, 377-379, 1977.

Singer, H. J., Matheson, L., Srubb, R., Newman, A., and Bouwer, S. D.: Monitoring space weather with the GOES magnetometers, in: SPIE Conference Proceedings, 2812, 299-308, GOES-8 and Beyond, edited by Washwell, E. R. 1996.

Song, P., Elphic, R. C., and Russell, C. T.: ISEE-1 and ISEE-2 observations of the oscillating magnetopause, Geophys. Res. Lett., 15, 744-747, 1988.

Southwood, D. J.: The hydromagnetic stability of the magnetospheric boundary, Planet. Space Sci., 16, 587-605, 1968.

Southwood, D. J.: Some features of field line resonances in the magnetosphere, Planet. Space Sci., 22, 483-491, 1974.
Southwood, D. J.: The ionospheric signature of flux transfer events, J. Geophys. Res., 92, 3207-3213, 1987.

Southwood, D. J., Farrugia, C. J., and Saunders, M. A.: What are flux transfer events?, Planet. Space Sci., 36, 503-508, 1988.

Spreiter, J. R., Summers, A. L., and Alksne, A. Y.: Hydromagnetic flow around magnetosphere, Planet. Space Sci., 14, 223253, 1966.

Spreiter, J. R. and Stahara, S. S.: A new predictive model for determining solar wind-terrestrial interactions, J. Geophys. Res., 85, 6769-6777, 1980.

Wei, C. Q. and Lee, L. C.: Ground magnetic signatures of moving elongated plasma clouds, J. Geophys. Res., 95, 2405-2418, 1990.

Wild, J. A., Cowley, S. W. H., Davies, J. A., Khan, H., Lester, M., Milan, S. E., Provan, G., Yeoman, T. K., Balogh, A., Dunlop, M. W., Fornacon, K.-H., and Georgescu, E.: First simultaneous observations of flux transfer events at the high-latitude magnetopause by the Cluster spacecraft and pulsed radar signatures in the conjugate ionosphere by the CUTLASS and EISCAT radars, Ann. Geophys., 19, 1491-1508, 2001.

Williams, D. J.: Magnetopause characteristics inferred from threedimensional energetic particle distributions, J. Geophys. Res., 84, 101-104, 1979.

Williams, D. J.: Magnetopause characteristics at 08:40-10:40 h local time, J. Geophys. Res., 85, 3387-3395, 1980.

Wright, A. N. and Richard, G. J.: A numerical study of resonant absorption in a magnetohydrodynamic cavity driven by a broadband spectrum, Astrophys. J., 444, 458-470, 1995.

Yumoto, K., Tanaka, Y., Oguti, T., Shiokawa, K., Yoshimura, Y., Isono, A., Fraser, B. J., Menk, F. W., Lynn, J. W., Seto, M., and $210^{\circ} \mathrm{MM}$ magnetic meridian observation group: Globally coordinated magnetic observations along $210^{\circ}$ magnetic meridian during STEP period: 1. Preliminary results of low-latitude Pc3's, J. Geomag. Geoelectr., 44, 261-276, 1992.

Yumoto, K. and the CPMN Group: Characteristics of Pi 2 magnetic pulsations observed at the CPMN stations: A review of the STEP results, Earth Planets Space, 53, 981-992, 2001. 